\title{
Scaling craters in carbonates: Electron paramagnetic resonance analysis of shock damage
}

\author{
Carol A. Polanskey ${ }^{1}$ and Thomas J. Ahrens \\ Division of Geological and Planetary Sciences, California Institute of Technology, Pasadena
}

\begin{abstract}
Carbonate samples from the 8.9-Mt nuclear (near-surface explosion) crater, OAK, and a terrestrial impact crater, Meteor Crater, were analyzed for shock damage using electron paramagnetic resonance (EPR). Samples from below the OAK apparent crater floor were obtained from six boreholes, as well as ejecta recovered from the crater floor. The degree of shock damage in the carbonate material was assessed by comparing the sample spectra to spectra of Solenhofen and Kaibab limestone, which had been shocked to known pressures. Analysis of the OAK Crater borehole samples has identified a thin zone of allocthonous highly shocked (10-13 GPa) carbonate material underneath the apparent crater floor. This $\sim 5$ - to 15 -m-thick zone occurs at a maximum depth of $\sim 125 \mathrm{~m}$ below current seafloor at the borehole, sited at the initial position of the OAK explosive, and decreases in depth towards the apparent crater edge. Because this zone of allocthonous shocked rock delineates deformed rock below, and a breccia of mobilized sand and collapse debris above, it appears to outline the transient crater. The transient crater volume inferred in this way is found to be $3.2 \pm 0.2 \times 10^{6} \mathrm{~m}^{3}$, which is in good agreement with a volume of $5.3 \times 10^{6} \mathrm{~m}^{3}$ inferred from gravity scaling of laboratory experiments [Schmidt et al., 1986]. A layer of highly shocked material is also found near the surface outside the crater. The latter material could represent a fallout ejecta layer. The ejecta boulders recovered from the present crater floor experienced a range of shock pressures from $\sim 0$ to $15 \mathrm{GPa}$ with the more heavily shocked samples all occurring between radii of 360 and $\sim 600 \mathrm{~m}$. Moreover, the fossil content, lithology and $\mathrm{Sr}$ isotopic composition all demonstrate that the initial position of the bulk of the heavily shocked rock ejecta sampled was originally near surface rock at initial depths in the 32 to $45-\mathrm{m}$ depth (below sea level) range. The EPR technique is also sensitive to prehistoric shock damage. This is demonstrated by our study of shocked Kaibab limestone from the 49,000-year-old Meteor (Barringer) Crater Arizona. We found shock damage present in the $\beta$ member of the Kaibab Formation exposed in the crater walls corresponding to peak shock stress in the $0.3-$ to $0.6 \mathrm{GPa}$ range. Carbonate ejecta recovered from within the crater experienced shock pressures of up to $0.6 \mathrm{GPa}$. Assuming shock damage levels of 0.3 to $0.6 \mathrm{GPa}$ for the lightly shocked carbonate on the walls of the Meteor crater, combined with the shock pressure versus distance model of Moss [1988] and Lamb et al. [1991], Meteor Crater impact energies of 2.4 to $8.9 \mathrm{Mt}$ are obtained. This approximately agrees with energies of 3.3 to $7.1 \mathrm{Mt}$ calculated from the crater scaling of Schmidt and Housen [1987].
\end{abstract}

\section{Introduction}

We analyzed shock deformation in carbonate samples taken from OAK Crater, an 8.9-Mt nuclear near-surface explosion crater located on Enewetak Atoll in the equatorial Pacific Ocean, and Meteor (Barringer) Crater, a terrestrial impact crater located near Flagstaff, Ari-

\footnotetext{
${ }^{1}$ Now at Jet Propulsion Laboratory, Pasadena, California.
}

Copyright 1994 by the American Geophysical Union.

Paper number 93JE03574.

0148-0227/94/93JE-03574\$05.00 zona. Electron paramagnetic resonance (EPR) spectrometry was used to determine the peak shock stress experienced by carbonate samples from both craters. Laboratory calibration experiments were used to relate degradation of EPR spectra to shock pressure levels. The OAK results are based on EPR spectra from 136 samples taken from six boreholes within and around the crater and 18 ejecta samples recovered from the crater floor. The sampling of Meteor Crater was less comprehensive and consists of eight samples from the crater wall, 12 samples from the continuous ejecta blanket, and eight miscellaneous samples. The Meteor Crater study presented here, although less complete, demonstrates, for the first time, the feasibility of applying the 
EPR analysis technique to geologically young terrestrial impact craters.

Earlier work relating EPR data to shock deformation was developed by Vizgirda et al. [1980] using core material from beneath a $18 \mathrm{kt}$ near-surface explosion, CACTUS Crater. Their work demonstrated a linear relationship between shock pressure and the hyperfine splitting in the EPR spectra that originated from $\mathrm{Mn}^{2+}$ substituting as an impurity for $\mathrm{Ca}^{2+}$ in the calcite component of the carbonate. CACTUS is a bowl-shaped crater, and the results of the EPR analysis were fit to a power curve directly relating sample depth to hyperfine splitting. This paper expands upon the previous calibration technique and extends its application to the study of larger, gravity-dominated, craters.

In this study, shock pressures were determined for the carbonate samples from OAK Crater by numerically comparing the sample spectrum to standard spectra of the well-consolidated Solenhofen limestone (rather than coral media), which had been shocked to known pressures in the laboratory. Similarly, several experimentally shocked Kaibab samples were used as a pressure calibration for the Meteor Crater samples. The present approach employs improvements in data reduction methods, as well as greater EPR signal strength.

We believe the EPR technique described here can be a useful tool in the analysis of other terrestrial impact craters. Of the 150 terrestrial craters suspected to be impact structures [Grolier, 1985], at least 27 were formed within carbonate target rock [Crieve, 1982; Short and Bunch, 1968]. Meteor Crater was formed in sedimentary rocks containing the Kaibab limestone, a sandy dolomitic limestone [Shoemaker and Kieffer, 1974]. The Kaibab Formation makes up a significant portion of the crater wall and is strongly represented in the continuous ejecta blanket.

Although both OAK and Meteor craters have similar final apparent diameters (1200 m versus $1100 \mathrm{~m}$, respectively); OAK is much shallower (60 m versus $197 \mathrm{~m}$, respectively). OAK crater is shallower because of extensive postexplosion modification [cf. Henry and Wardlaw, 1987; Tremba et al., 1990].

In this paper, we describe properties of the EPR spectrum of $\mathrm{Mn}^{2+}$ in carbonate rocks and the details of how the spectra were obtained and analyzed. Then we discuss the specifics of the OAK and Meteor crater sample analysis. These results are used to define the OAK transient crater, and also compared to volumes obtained with Schmidt et al. scaling laws. In the case of Meteor Crater, we use the peak shock pressure experienced by rocks from the crater walls to infer impact energy and compare this to the values obtained using the scaling law of Schmidt and Housen [1987], as well as the results of previous numerical simulations.

\section{The EPR Spectrum of $\mathrm{Mn}^{2+}$ in Carbonates}

\section{Powdered Calcite}

The EPR (also referred to as electron spin resonance, or ESR) spectrum of powdered calcium carbon- ate, $\mathrm{CaCO}_{3}$, is a result of $\mathrm{Mn}^{2+}$ substituting for $\mathrm{Ca}^{2+}$ in a single site in the crystal lattice. The theory of $\mathrm{Mn}^{2+}$ resonance absorption in single-crystal calcite is described by Hurd et al. [1954]. The $\mathrm{Mn}^{2+}$ ion has an effective spin of $S=\frac{5}{2}$ and a nuclear spin of $I=\frac{5}{2}$,

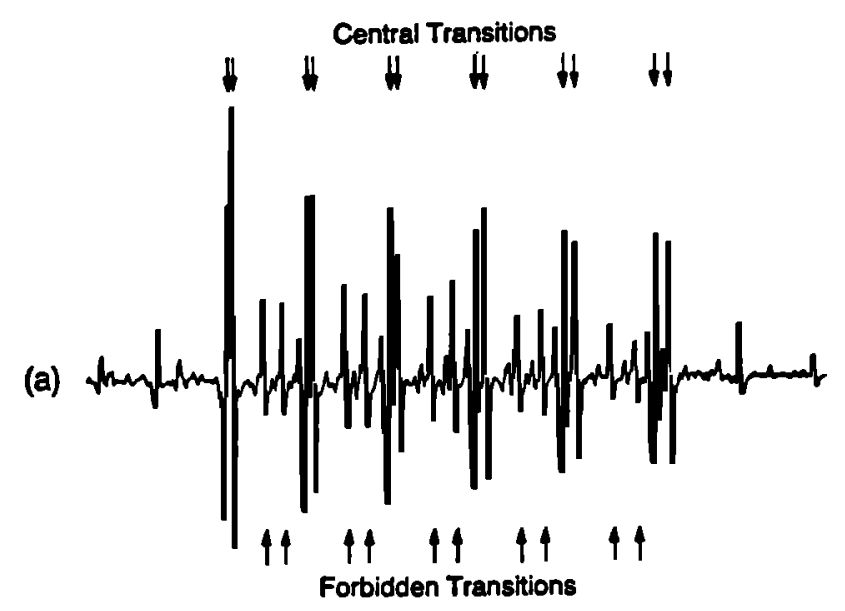

(b)

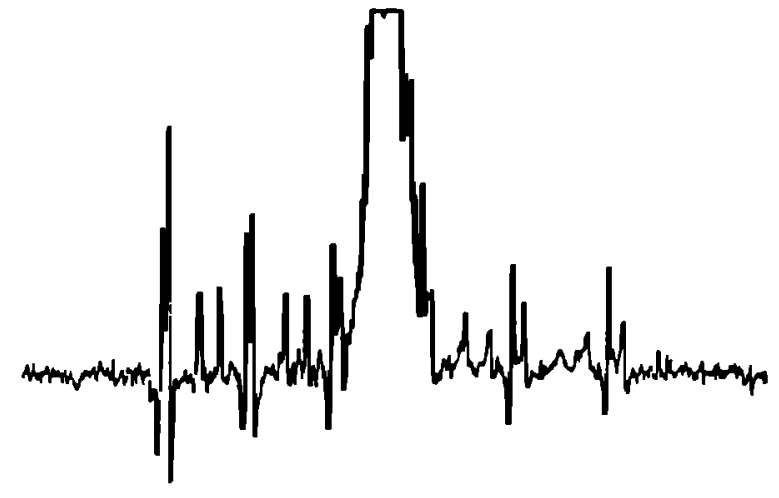

(c)
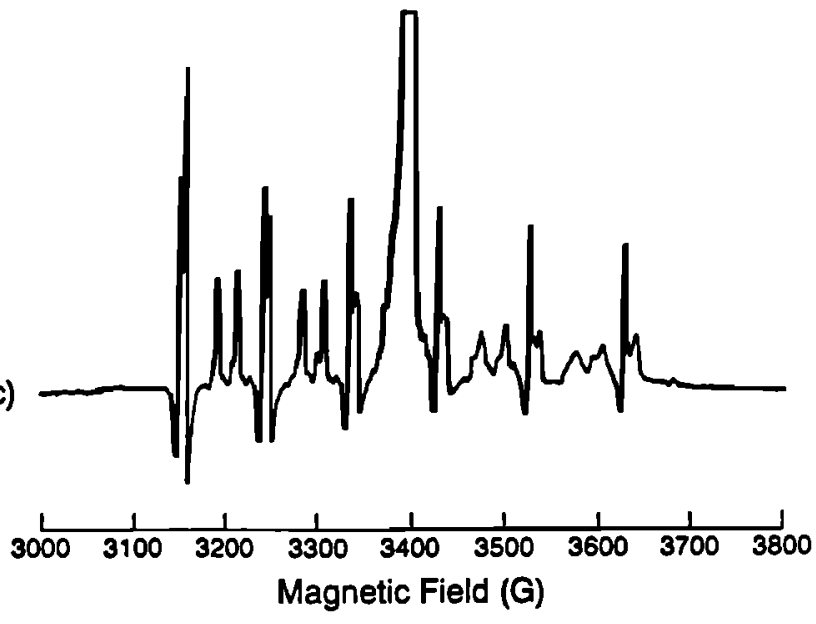

Figure 1. (a) EPR spectrum of powdered singlecrystal calcite. The central transitions are due to $M_{S}=$ $\pm \frac{1}{2}, \Delta m_{I}=0$, where $M_{S}$ and $m_{I}$ are the electronic and nuclear magnetic quantum numbers, respectively. The forbidden transitions occur when $\Delta m_{I}=1$. (b) EPR spectrum, unshocked coral limestone, $50 \mathrm{~m}$ bsl, OCT-5 borehole (see Figure 5 for hole location). (c) EPR spectrum, $65 \mathrm{~m}$ bsl OCT- $5 \mathrm{~b}$, shocked to $4.8 \pm$ $6 \mathrm{GPa}$ by OAK explosion. The central, 3400-G peak in Figures $1 \mathrm{~b}$ and $1 \mathrm{c}$ is the result of natural radiation damage [see Vizgirda et al., 1980]. 
which give rise to a total of 30 transitions. The calcite spectrum exhibits both fine and hyperfine structure but is dominated by the six hyperfine peaks from the central transitions $M_{S}= \pm \frac{1}{2}$, and $\Delta m_{I}=0$, where $M_{S}$ is the electronic magnetic quantum number, and $m_{I}$ is the nuclear magnetic quantum number. The hyperfine peak splitting results from the coupling between electronic and nuclear magnetic moments [Hurd et al., 1954]. Another feature of the spectrum is the forbidden transition peaks, $\Delta m_{I}=1$, which are less prominent and occur in pairs between the central transitions [Mankowitz and Low, 1970]. The spectrum of a powdered sample of single-crystal calcite, Iceland spar, is shown in Figure 1. The central allowed transitions are labeled along with the smaller forbidden transitions. Of particular interest to this study are the two outermost peak doublets at the lowest and highest magnetic field positions of the sextet.

\section{Coralline Limestone Samples from OAK Crater}

The "carbonate" in the OAK crater is a coralline limestone composed of a mixture of calcite and aragonite. Blanchard and Chasteen [1976] have studied both the calcite and the aragonite components of a sea shell using EPR methods. The spectra of $\mathrm{Mn}^{2+}$ in the calcite portion of the shell resemble that of single-crystal calcite; however, no EPR signal was obtained at either room temperature or liquid nitrogen temperatures for powdered samples of the aragonitic portion. Work by Low and Zeira [1972] also describe the lack of an EPR spectrum that is due to $\mathrm{Mn}^{2+}$ in both single crystals and powdered aragonite. They also state that calcite formed from aragonite at low temperatures, such as the case in the Enewetak samples, shows the typical $\mathrm{Mn}^{2+}$ calcite spectrum. Therefore, it is assumed that the spectra obtained in this study (e.g., Figure $2 b$ ) are due entirely to the calcite component of the sample.
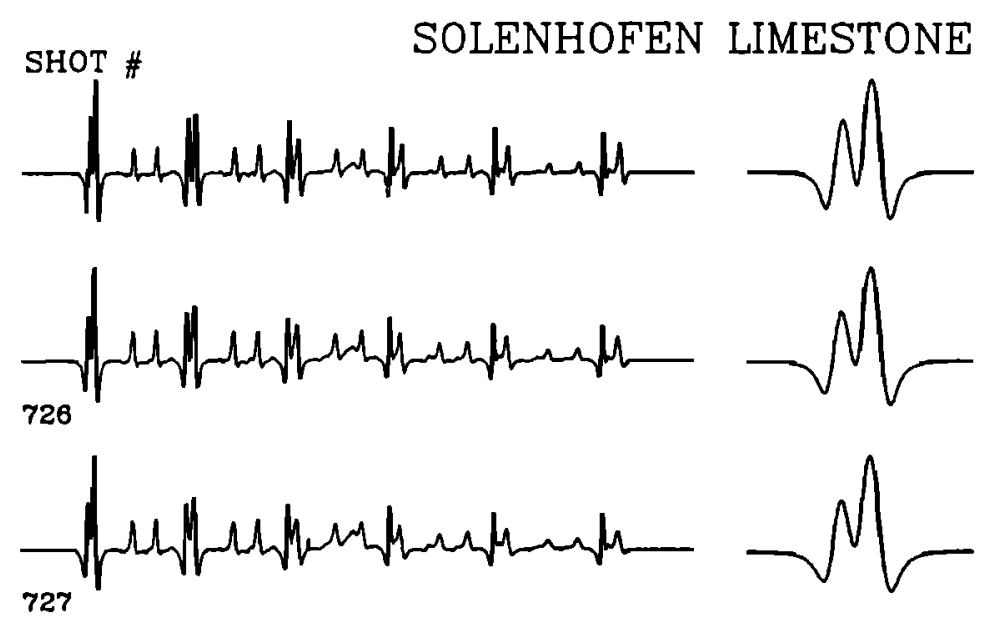

PRESSURE
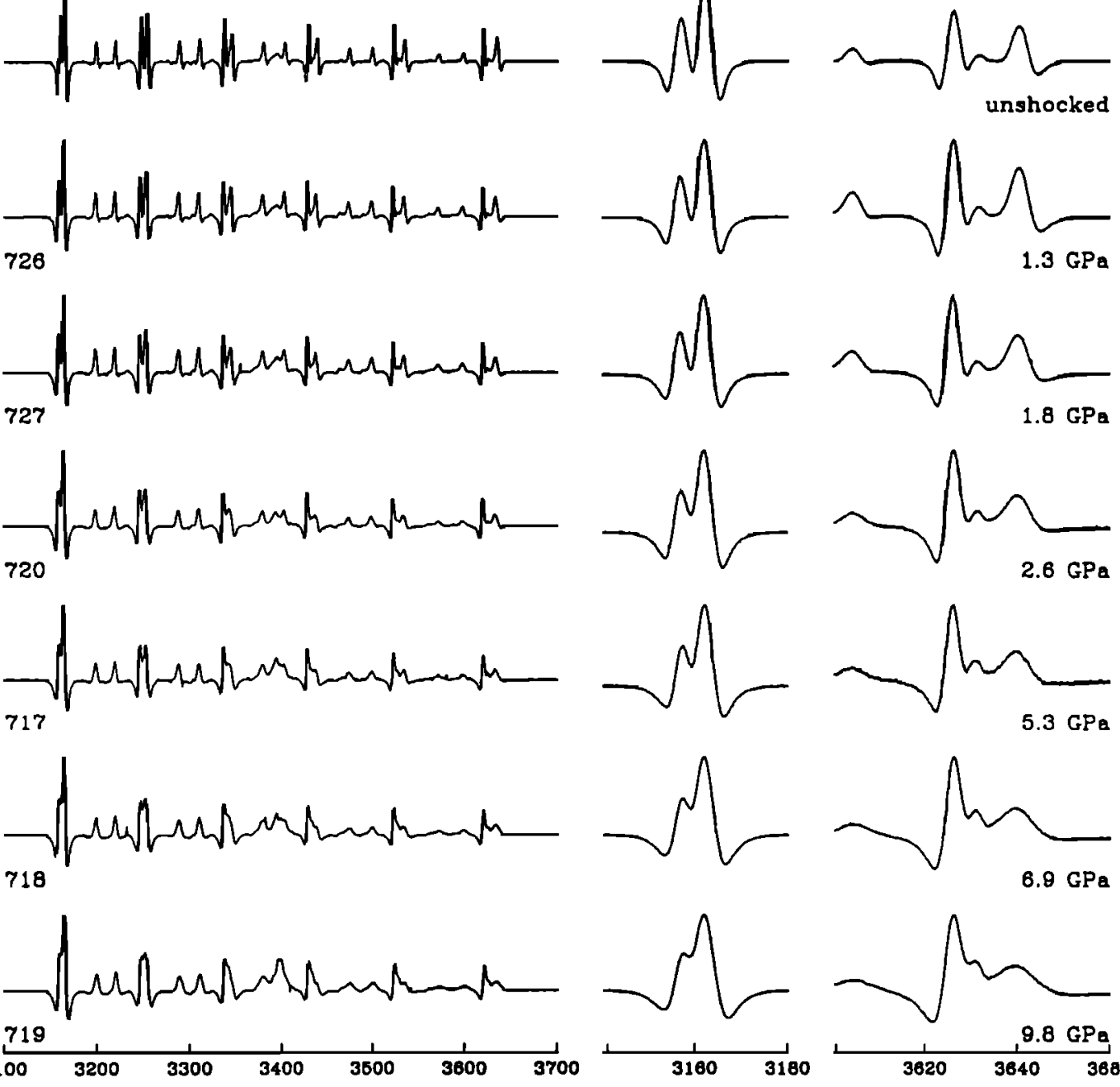

\section{MAGNETIC FIELD (G)}

Figure 2a. Comparison of Solenhofen limestone spectra shocked in the laboratory. The first column shows the full spectrum centered at $3400 \mathrm{G}$, while the second and third columns show the high-resolution spectra of the lowest and highest field components centered at $3160 \mathrm{G}$ and $3630 \mathrm{G}$, respectively. 

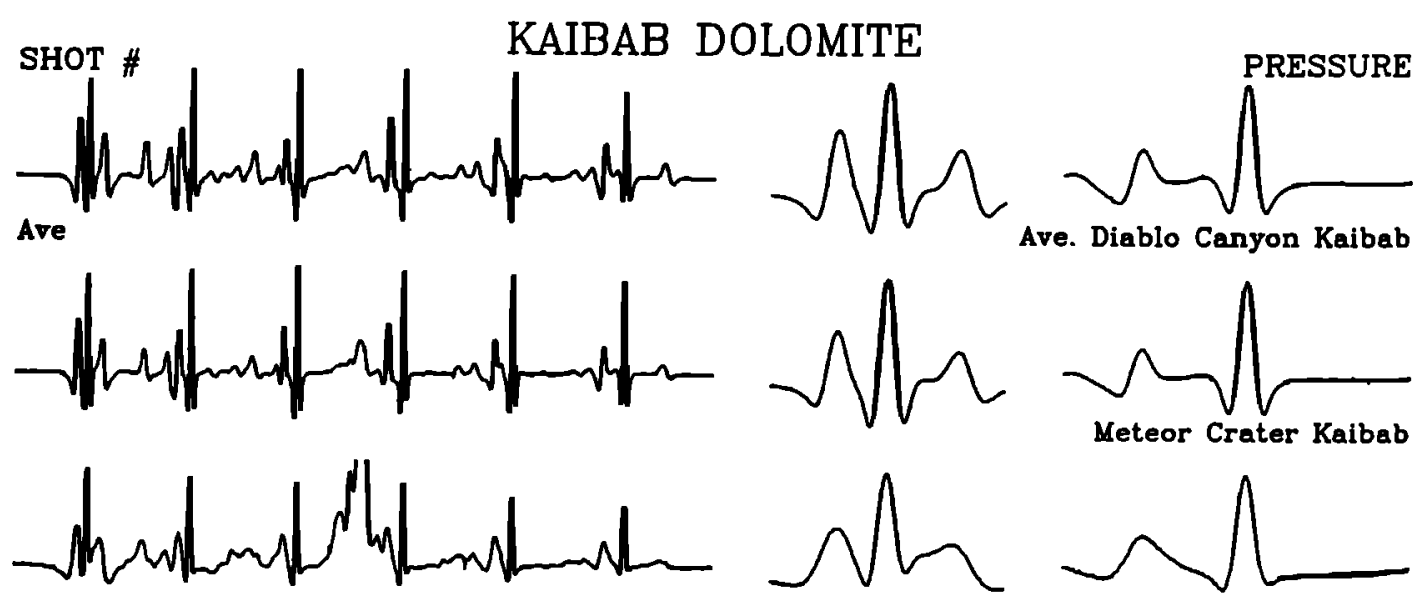

729

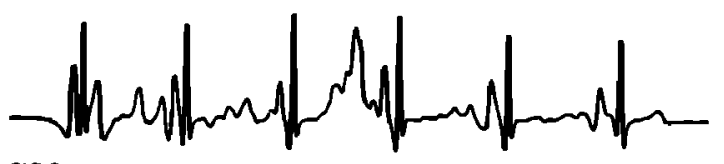

726
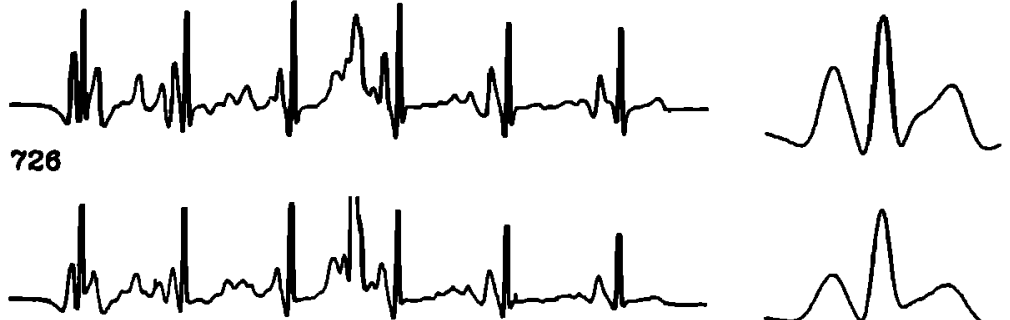

$0.8 \mathrm{GPa}$

731
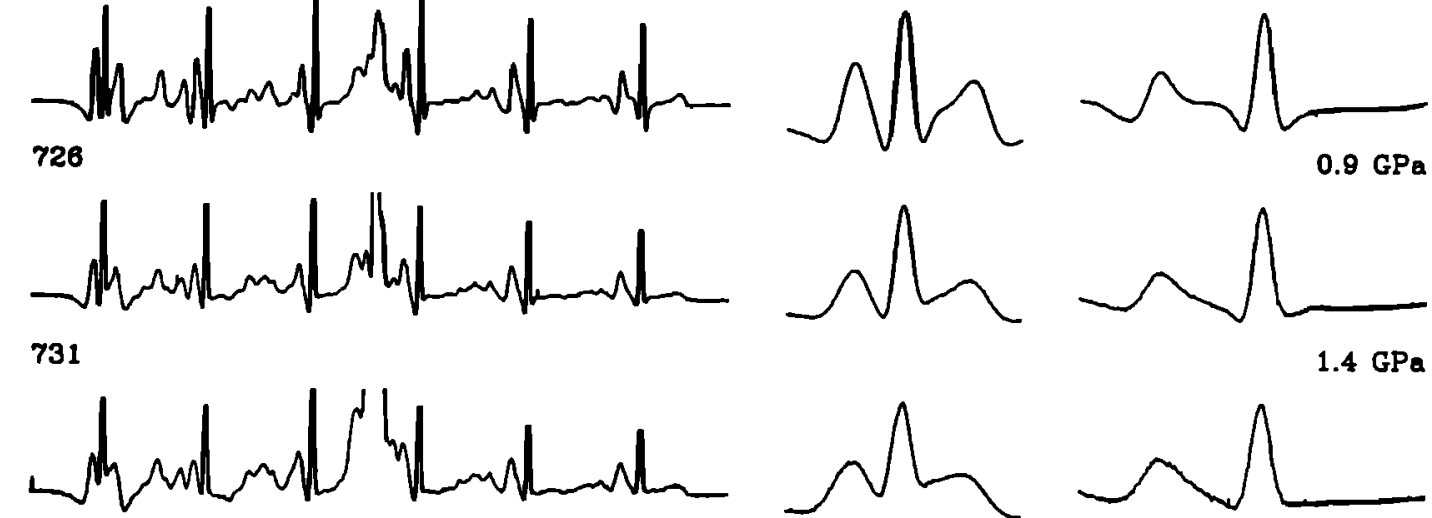

$1.4 \mathrm{GPa}$
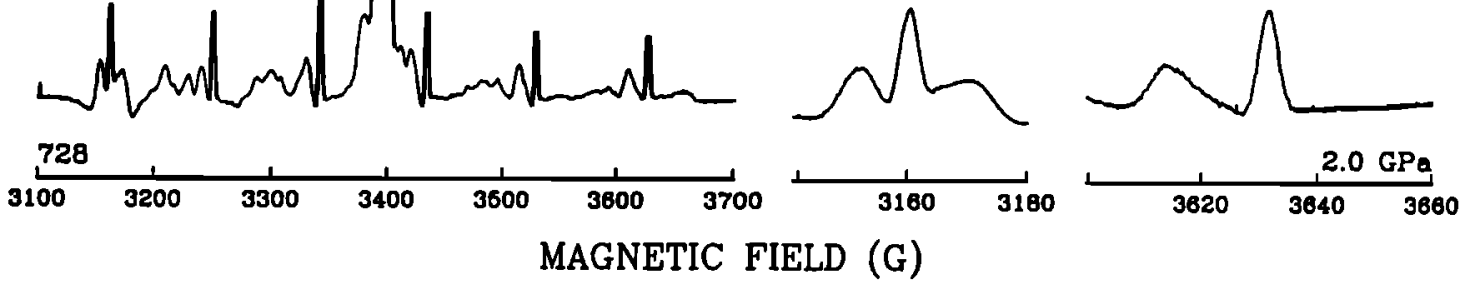

Figure 2b. Comparison of Kaibab limestone spectra shocked in the laboratory. The first column shows the full spectrum centered at $3400 \mathrm{G}$, while the second and third columns show the highresolution spectra of the lowest and highest field components centered at $3160 \mathrm{G}$ and $3630 \mathrm{G}$, respectively.

\section{Kaibab Dolomitic Limestone Samples from Me- teor Crater}

Meteor Crater was formed in sedimentary bedrock containing the Kaibab Formation. The Kaibab consists of fossiliferous marine sandy dolomites, dolomitic limestones, and calcareous sandstones [Shoemaker and Kieffer, 1974]. This formation is exposed on the crater walls and is part of the remaining continuous ejecta blanket. The EPR spectrum of $\mathrm{Mn}^{2+}$ in dolomite is similar to the OAK carbonates; however, it differs in two important respects. First, the dolomite spectrum is affected by the presence of two different cations, $\mathrm{Mg}^{2+}$ and $\mathrm{Ca}^{2+}$, within the structure [Wildeman, 1970]. Second, because of the difference between the $\mathrm{Mg}^{2+}$ the $\mathrm{Mn}^{2+}$ impurities occupy the $\mathrm{Mg}^{2+}$ sites as well as the $\mathrm{Ca}^{2+}$ sites. Past measurements indicate a preference for $\mathrm{Mn}^{2+}$ to occupy the $\mathrm{Mg}$ site over the $\mathrm{Ca}$ site [Vinokurov et al., 1961; Prissok and Lehmann, 1986].
Sample Preparation and Spectrometer Measurements

Carbonate samples were ground into a coarse powder and placed into Wilmad 707SQ fused-quartz EPR tubes. EPR spectra were taken at room temperature with a Varian E-Line Century Series spectrometer. The $\mathrm{Mn}^{2+}$ feature occurs from approximately 3150 to $3650 \mathrm{G}$, and is centered near $3400 \mathrm{G}$ (where the spectroscopic splitting factor is $g=2$ ). The spectrometer was set at $9.56 \mathrm{GHz}$, microwave power of $20 \mathrm{~mW}$, modulation amplitude of $3.2 \mathrm{G}$, and time constant of $0.25 \mathrm{~s}$, and operated in the second derivative mode.

\section{Shock wave Calibration Experiments}

The calibration data set is a combination of three series of shock wave experiments. The first series consisted of carbonate samples from CACTUS crater 
shocked by us previously [Vizgirda et al., 1980]. The samples were taken from two different depths, 10 and 146 feet ( 3 and $44.5 \mathrm{~m}$ ) from the borehole XRU-3 located outside of CACTUS crater on Enewetak Atoll. The principal motivation for reprocessing these samples was to demonstrate that the shock effects observed by Vizgirda et al. had remained unchanged. New spectra were taken of each sample, and the results confirmed that the effect of shock on the hyperfine splitting had not altered on the timescale of a decade.

The second series of experiments provided the data used to develop the present pressure calibration technique. The pressure calibration for the coralline Enewetak carbonates was based on six Solenhofen limestone samples shocked to known pressures in the laboratory. Solenhofen limestone was chosen as a calibration standard for the OAK analysis because its EPR spectrum, which was also due to $\mathrm{Mn}^{2+}$ substitution, is orders of magnitude more intense than the spectra from the Enewetak carbonates. The limestone is also more chemically homogeneous, although it is still a polycrystalline material. We note that the carbonate material at Enewetak was saturated, whereas the calibration experiments were conducted on dry samples. What effect water saturation had on the calibrations is uncertain.

The third series of calibration samples consisted of shocked Kaibab dolomitic limestone taken from the walls of Meteor Crater. This calibration was used to determine the degree of shock damage in more heavily shocked samples from Meteor Crater. However, the standard Kaibab comparison spectra were constructed from averages of spectra from five samples taken from Diablo Canyon. Diablo Canyon is $\approx 10$ crater radii away from the crater, so that the samples should not have been affected by the impact. The Kaibab EPR spectra also have a strong $\mathrm{Mn}^{2+}$ signature of similar amplitude to the Solenhofen limestone.

Cores of sample material, $0.64 \mathrm{~cm}$ in diameter, were cut into cylinders $1 \mathrm{~cm}$ in length and pressed into stainless steel sample chambers. The rear of the sample chamber cup was enclosed by a stainless steel plug, which was notched to vent any impact-generated gases. The sample chamber was then inserted into a large stainless steel momentum trap and mounted with the vacuum chamber of the Caltech $40-\mathrm{mm}$ propellant gun apparatus. Lexan projectiles containing flyer plates of aluminum or lexan impacted the target assembly at velocities between 0.8 and $1.6 \mathrm{~km} / \mathrm{s}$ to yield initial shock pressures of 1.3 to $9.8 \mathrm{GPa}$ and 0.7 to $2.0 \mathrm{GPa}$ for the Solenhofen and Kaibab samples, respectively. Initial shock pressure, rather than final, reverberated shock pressure is quoted because most of the entropy generated by the shock, and hence the shock damage, is associated with the initial shock wave [Lange and Ahrens, 1986].

Shock pressures were calculated using the projectile velocities and the impedance match technique (Table 1 ) [Stöffler, 1972]. Here $\mathrm{C}_{o}$ and $s(6)$ are the usual parameters in a linear shock velocity-particle fit to Hugoniot data [Marsh, 1980]. The average bulk density of the limestone samples was $2.61 \mathrm{~g} / \mathrm{cm}^{3}$, and the Hugoniot data for Solenhofen limestone were taken from Tyburczy and Ahrens [1986] and Ahrens and Gregson [1964]. A Hugoniot for the alpha member of the Kaibab limestone $\left(2.22 \mathrm{~g} / \mathrm{cm}^{3}\right)$ was measured by Isbell et al. [1966] for shock pressures between 30 and $112 \mathrm{GPa}$.

\section{Description of Shocked Solenhofen Limestone Spectra}

The spectra of shocked limestone (Figure 2a) have been normalized such that the highest peak of each sample is equal to one. The shocked limestone spectra not only reflect the decrease in the hyperfine splitting observed earlier by Vizgirda et al. [1980] in the carbonate spectra, but also reveal that the relative signal strength and width of the two peaks in each hyperfine component vary in a consistent manner with increasing pressure. It is clear from the second and third columns in Figure 2a that the outermost peak in each doublet decreases in relative amplitude and broadens with increasing shock pressure. This alone may be the cause of the decrease in splitting observed with exposure to increasing shock pressure.

The specific behavior of the peaks in the high-field doublet of the carbonate samples from OAK crater is less obvious and becomes difficult to detect in samples subjected to high shock pressures, because of the high aragonite content and poor ordering in the calcite (see

Table 1. Shock Wave Data Used in Present Study

\begin{tabular}{lccc}
\hline \multicolumn{1}{c}{ Material } & Density, $\mathrm{g} / \mathrm{cm}^{3}$ & $C_{0}, \mathrm{~km} / \mathrm{s}$ & $\mathrm{s}$ \\
\hline Lexan $^{*}$ & 1.196 & 2.631 & 1.295 \\
${\text { Aluminum }(2024)^{*}}_{\text {Steel }^{*}(304)^{*}}$ & 2.784 & 5.370 & 1.290 \\
Solenhofen limestone $^{\dagger}$ & 7.890 & 4.580 & 1.490 \\
Kaibab dolomitic limestone $^{\ddagger}$ & 2.61 & 3.269 & 1.796 \\
\hline
\end{tabular}

*Data from Marsh [1980]

†Data from Tyburczy and Ahrens [1986]; Ahrens and Gregson [1964]

†Data from Isbell et al. [1966] 
Figure 1c). The high-field doublet in heavily shocked samples is not resolvable (as seen in the Solenhofen limestone sample shocked to $9.8 \mathrm{GPa}$ (Figure 2a)). We note that the amplitude of the entire spectrum tends to decrease with increasing shock pressure. This effect is much more obvious in the OAK samples than in the Solenhofen limestone. The inability to resolve the highfield doublet in heavily shocked samples may be in part due to the poor or disordered crystalline nature of the organically produced, and in some cases, diagenetic calcite and $\mathrm{Mg}$ calcite (the result of the possible effects of the $\mathrm{Mg}^{2+}$ substitution on the EPR method was not addressed in this study) within the OAK sediments versus the well-crystallized Solenhofen limestone. In addition, the carbonate mineralogy of the shallow OAK samples, i.e., $<350-400 \mathrm{ft}(106-122 \mathrm{~m})$ below seafloor, is predominantly aragonite (70-80\%) (see, Ristvet and Tremba in Henry and Wardlaw [1987]); hence the calcite content is low, which also may influence the $\mathrm{Mn}^{2+} \mathrm{EPR}$ analyses.

\section{Description of Shocked Kaibab Limestone Spec- tra}

Similarly, the series of shocked Kaibab samples (Table 2) is shown in Figure 2b. One obvious difference in the Kaibab spectra is that the low-field component of the sextet is a triplet rather than a doublet. This is not understood in detail. In general, although the sextet of six hyperfine components is still present, each of its components differs from its counterpart in the Solenhofen spectrum. In addition, the forbidden transitions are not as well defined. Despite these differences, the effect of increasing shock pressure appears to have a similar effect on the spectra. Both the low- and the high-field components broaden with increasing shock pressure, and the relative heights of the lesser peaks in each sextet decrease with respect to the highest peak.

\section{Pressure Calibration by Differencing Spectra}

The previous calibration technique of Vizgirda et al. [1980] relied on measuring the separation, in Gauss, of the two peaks of the highest field component of each spectrum. The splitting of the hyperfine peak, HPS, was related to shock pressure, $P$, by the relationship

$$
H P S(G)=-0.60 P(G P a)+13.85 \quad \text { (high field). }
$$

Although the decrease in the splitting of the peaks is most evident in the high-field hyperfine component, the signal strength of this peak is also the lowest. Therefore, as the signal intensity decreases, the error in measuring hyperfine peak splitting increases. The following technique was developed to incorporate the variations in hyperfine splitting as well as relative peak amplitudes and widths. In addition, the analysis will work equally well for the lowest field component of the spectrum, which generally has a higher amplitude than the highest field component.

The standard chosen for the Solenhofen limestone and Enewetak carbonates was single-crystal calcite, while the the standard for the Meteor Crater samples was the wall sample used as material for the shock wave experiments. Both high-resolution spectra from each end of the spectrum were used in the comparison. The digital spectra consisted of 1000 amplitude values evenly spaced over a 100-G field range. Both sample and standard spectra were first normalized by the amplitude of the highest peak of the hyperfine spectrum. The sample spectrum was then translated along the magnetic field axis until the position of its highest subpeak coincided with that of the standard spectrum. Next, the absolute value of the difference in amplitude between the two

Table 2. Pressure and Integrated Difference (ID) Data for High-Resolution Spectra From Samples Shocked in Laboratory Recovery Experiments

\begin{tabular}{|c|c|c|c|}
\hline Shot Number & P, GPa & ID, Low Field & ID, High Field \\
\hline \multicolumn{4}{|c|}{ Solenhofen Limestone } \\
\hline - & 0.0 & 0.0518 & 0.1187 \\
\hline 726 & 1.3 & 0.0585 & 0.1375 \\
\hline 727 & 1.8 & 0.0709 & 0.1701 \\
\hline 720 & 2.6 & 0.0848 & 0.1924 \\
\hline 717 & 5.3 & 0.0951 & 0.2123 \\
\hline 718 & 6.9 & 0.1086 & 0.2324 \\
\hline 719 & 9.8 & 0.1322 & 0.2654 \\
\hline \multicolumn{4}{|c|}{ Kaibab Dolomite } \\
\hline- & 0.0 & 0.0251 & 0.0290 \\
\hline 729 & 0.8 & 0.0999 & 0.1610 \\
\hline 726 & 0.9 & 0.0588 & 0.0454 \\
\hline 731 & 1.4 & 0.0944 & 0.1709 \\
\hline 728 & 2.0 & 0.1334 & 0.2190 \\
\hline
\end{tabular}


spectra was calculated for each point over the extent of the doublet. Finally, these individual differences were summed to determine a measure of the "likeness" or the "unlikeness" of the sample spectrum to the standard. This number shall be referred to as the integrated difference, or ID, of the sample, which is given analytically by

$$
I D=\sum_{i=n_{0}}^{n_{0}+N} \frac{\left|Y_{\text {standard }}(i)-Y_{\text {sample }}(i)\right|}{N+1}
$$

where $n_{0}$ is the index of the amplitude array corresponding to a magnetic field value $20 \mathrm{G}$ below that of the highest peak of the standard spectrum. $Y_{\text {standard }}(i)$ and $Y_{\text {sample }}(i)$ are the normalized amplitudes of the standard and sample spectra, respectively, and $N$ is the number of data points that are integrated. In the case of the calcite spectra, $N$ was chosen as 400 , corresponding to $40 \mathrm{G}$. However, the high-field hyperfine peaks in the Kaibab spectra are broader than the limestone spectra, so the ID for these samples was calculated for $60 \mathrm{G}$, or $N=600$. The error in ID is determined by performing a similar calculation, where $Y_{\text {sample }}(i)$ are points in the flat baseline signal on either side of the $\mathrm{Mn}^{2+}$ peak.

Figure 3 illustrates the application of this procedure on two high-field hyperfine spectra from the limestone calibration experiments. The absolute value of the difference between the amplitudes at each point over a $40 \mathrm{G}$ range in magnetic field is shown in Figure $3 \mathrm{~b}$. Figures $3 \mathrm{c}$ and $3 \mathrm{~d}$ demonstrate the same technique applied to a limestone sample that has been shocked to $9.8 \mathrm{GPa}$. The error is determined by using the same scheme to calculate the integrated difference along a
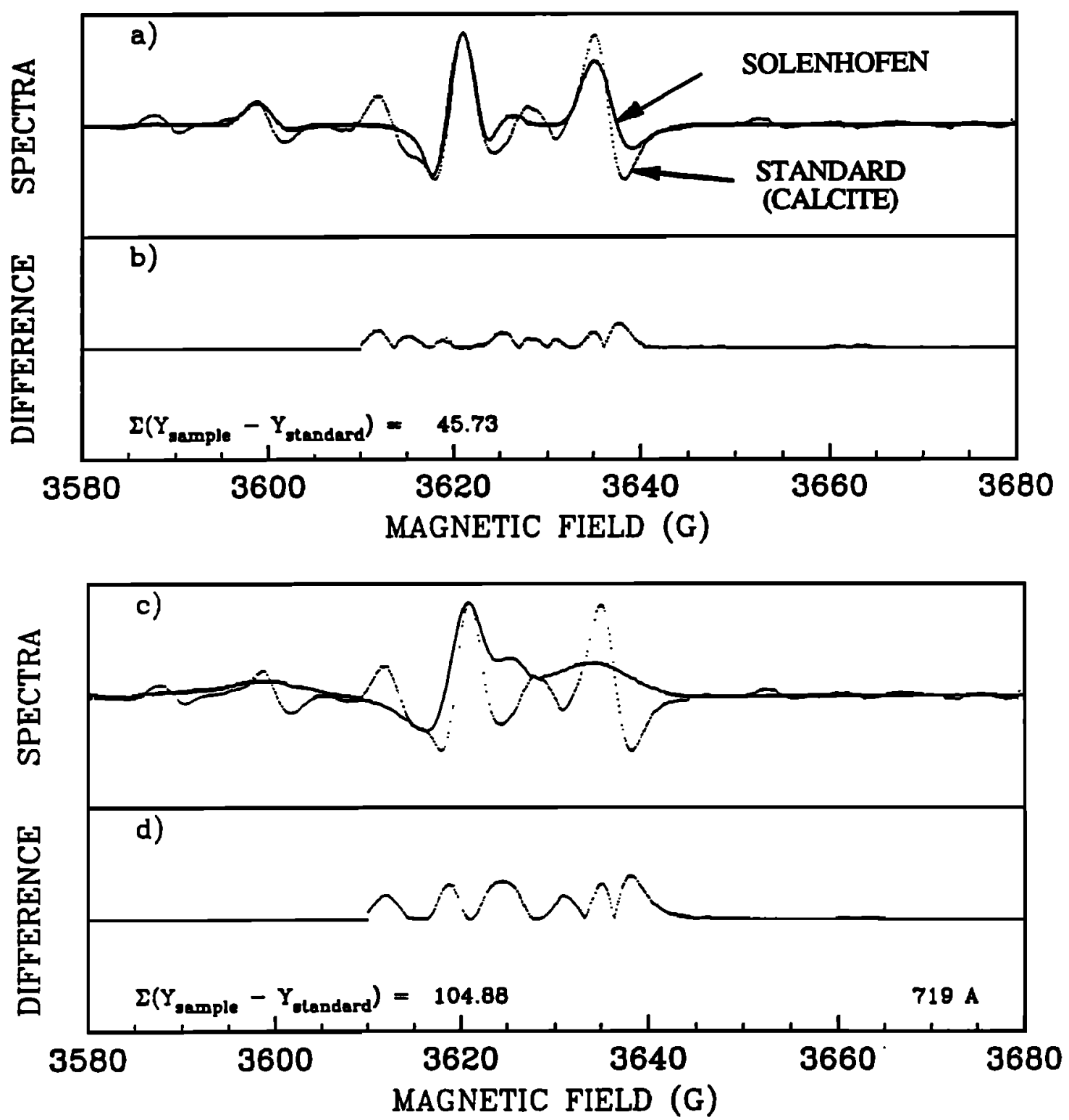

Figure 3. Example of the differencing technique, showing (a) an overlay of the standard (calcite) high-field hyperfine spectra and an unshocked Solenhofen limestone sample, and (b) a plot of the individual absolute differences at each point along the field. Figures $3 \mathrm{c}$ and $3 \mathrm{~d}$ are the same as Figures $3 \mathrm{a}$ and $3 \mathrm{~b}$ for limestone shocked to $9.8 \mathrm{GPa}$. 
flat portion of the spectrum. This value gives an estimate of the contribution of noise to the ID over the region containing the signal.

The results of these calculations for the limestone calibration experiments are plotted in Figure 4. The ID values are plotted versus pressure for both the low- and the high-field components of the spectrum. To determine the pressure to integrated-difference calibration, a line was fit to each data set, using linear least squares. The resulting equations are

$$
\begin{array}{cc}
P_{\text {Solenhofen }}(G P a)=116(I D)-5.97 & \text { low field; } \\
P_{\text {Solenhofen }}(G P a)=61.0(I D)-7.60 & \text { high field. }
\end{array}
$$

The correlation coefficients for the fit were 0.983 and 0.971 , respectively. Table 2 contains a list of the ID results for the limestone experiments. The average ID values are given for shots where several samples were analyzed. Using the calibration curves above, shock pressures were then assigned to the OAK carbonate samples. In general, the carbonate samples have a much weaker EPR signal than the limestone. Therefore, it was necessary to adjust the intercept of the calibration curves to compensate for the average ID value of the unshocked carbonate samples, so that zero pressure is, in fact, obtained. It follows that this method will then assign negative pressures to some samples because the previous adjustment was made to accommodate the "average" background noise. To avoid this obviously unphysical result, and because this technique is

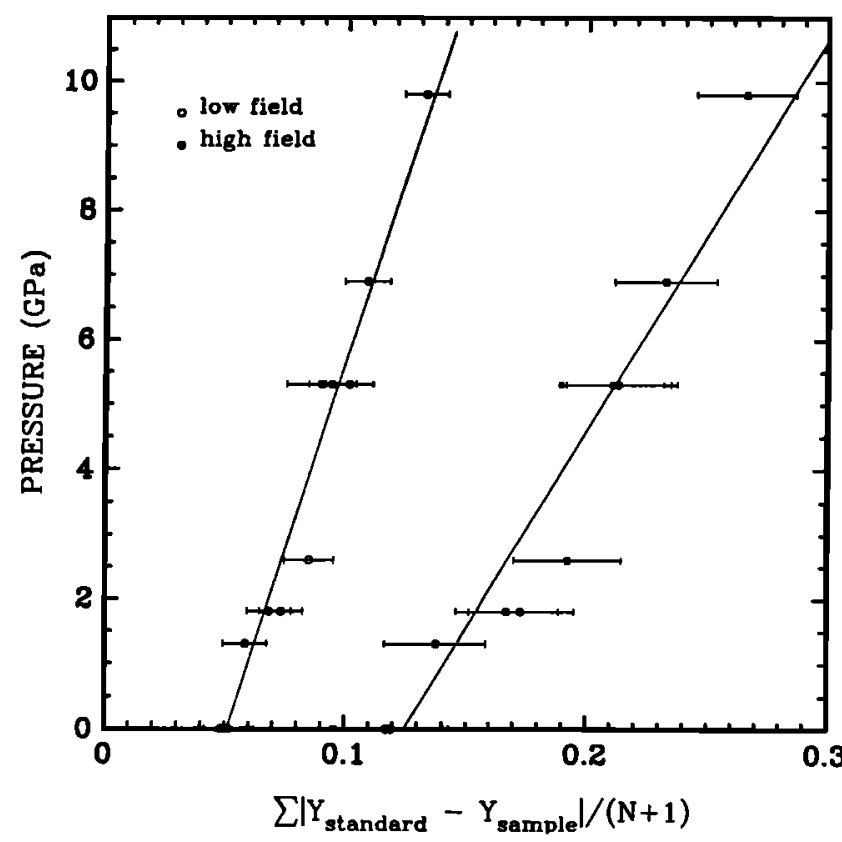

Figure 4a. Plot of the summed differences for the lowand high-field components of the Solenhofen limestone samples as a function of shock pressure. The ID value is calculated over a range of $40 \mathrm{G}$.

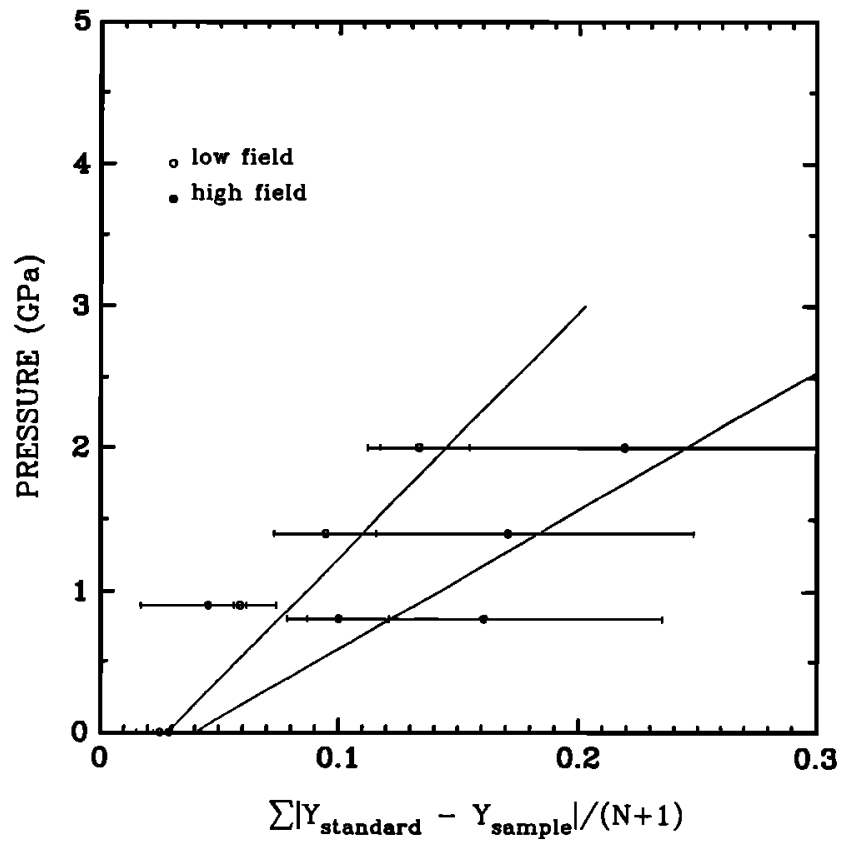

Figure 4b. Plot of the summed differences for the low- and high-field components of the Kaibab dolomitic limestone samples as a function of shock pressure. The ID value is calculated over a range of $60 \mathrm{G}$.

not extremely sensitive for low shock damage, all OAK samples with shock pressures calculated to be below $2.0 \mathrm{GPa}$ were classified simply as unshocked. Similarly, the high-pressure cutoff was chosen to be $15 \mathrm{GPa}$. This is necessary because the rocks were low in calcite content and there are no data for very high shock pressures, and the intensity of the carbonate spectrum is low even at $10 \mathrm{GPa}$. In most cases, shock pressures were calculated for each sample using both the low- and high-field components of the spectrum. These values were then averaged to determine the final calculated pressure.

Similarly, a calibration curve was determined for the Kaibab experiments (Figure 4b). However, the Kaibab data covered only the low end of the pressure range sampled in the Solenhofen experiments. The fit to the Kaibab data is

$$
\begin{array}{cc}
P_{\text {Kabab }}(G P a)=17.2(I D)-0.494 & \text { low field, } \\
P_{\text {Karbab }}(G P a)=9.77(I D)+0.391 & \text { high field, }
\end{array}
$$

where the correlation coefficients for these curves were 0.926 and 0.940 , respectively. The slopes of equations (3a) and (3b) are significantly less than the slopes calculated for the Solenhofen limestone experiments. One possible explanation is that this is the result of a sampling bias from computing the calibration for samples in the low-pressure regime. If the Solenhofen calibration was calculated based on only the data up to $2.6 \mathrm{GPa}$, the slopes would become 71.0 and 31.7 for the lowand high-field components, respectively. Another factor is that the width of each component of the hyperfine sextet of the Kaibab spectrum occurs over a greater 
range of magnetic field than its Solenhofen counterpart. This difference could contribute to higher ID values for Kaibab samples relative to Solenhofen samples experiencing similar shock pressures.

\section{OAK Crater}

OAK Crater is located at the northwest portion of the fringing reef at Enewetak Atoll in the Republic of the Marshall Islands. It was formed by an 8.9-Mt explosive device detonated $1.75 \mathrm{~m}$ above sea level on a landing craft utility hull approximately $4 \mathrm{~m}$ above the lagoon floor $\left(1 \mathrm{Mt}=4.18 \times 10^{22} \mathrm{ergs}\right)$ [Ristvet et al., 1977]. The present apparent crater has a maximum radius and depth of $875 \mathrm{~m}$ and $60 \mathrm{~m}$, respectively. A detailed description of OAK Crater and the geophysical and material studies performed can be found in Folger [1986] and Henry and Wardlaw [1987].

Enewetak Atoll is composed of 42 islands or islets on the Enewetak fringing reef. Some of these islands are transitory features and represent excess sediment production from the reef that are wind and wave deposited, and in some instances, stabilized by beachrock formation. A summary of their formation is discussed by Ristvet [1987]. The core samples from OAK were obtained through a drilling and coring effort performed from April through July 1985 [Henry et al., 1986]. The rock samples were provided in the form of drill cores 8.6 $\mathrm{cm}$ in inside diameter.

A system of geologic zones was defined by Henry and Wardlaw [1987] using the rock nomenclature of Dunham [1962] to describe the stratigraphy beneath the crater. The uppermost Alpha zone consists of late-stage sedimentation and slope failure along with material transported (possibly by hydraulic process) to the surface. The Beta 1 zone involves both early- and late-stage collapse rubble, and also includes some piped material. The Beta 2 zone is referred to as the transition sands. It has limited lateral extent and contains pulverized sand. Beneath the Beta 2 horizon, the rock of the Beta 3

\section{OAK CRATER BOREHOLES}

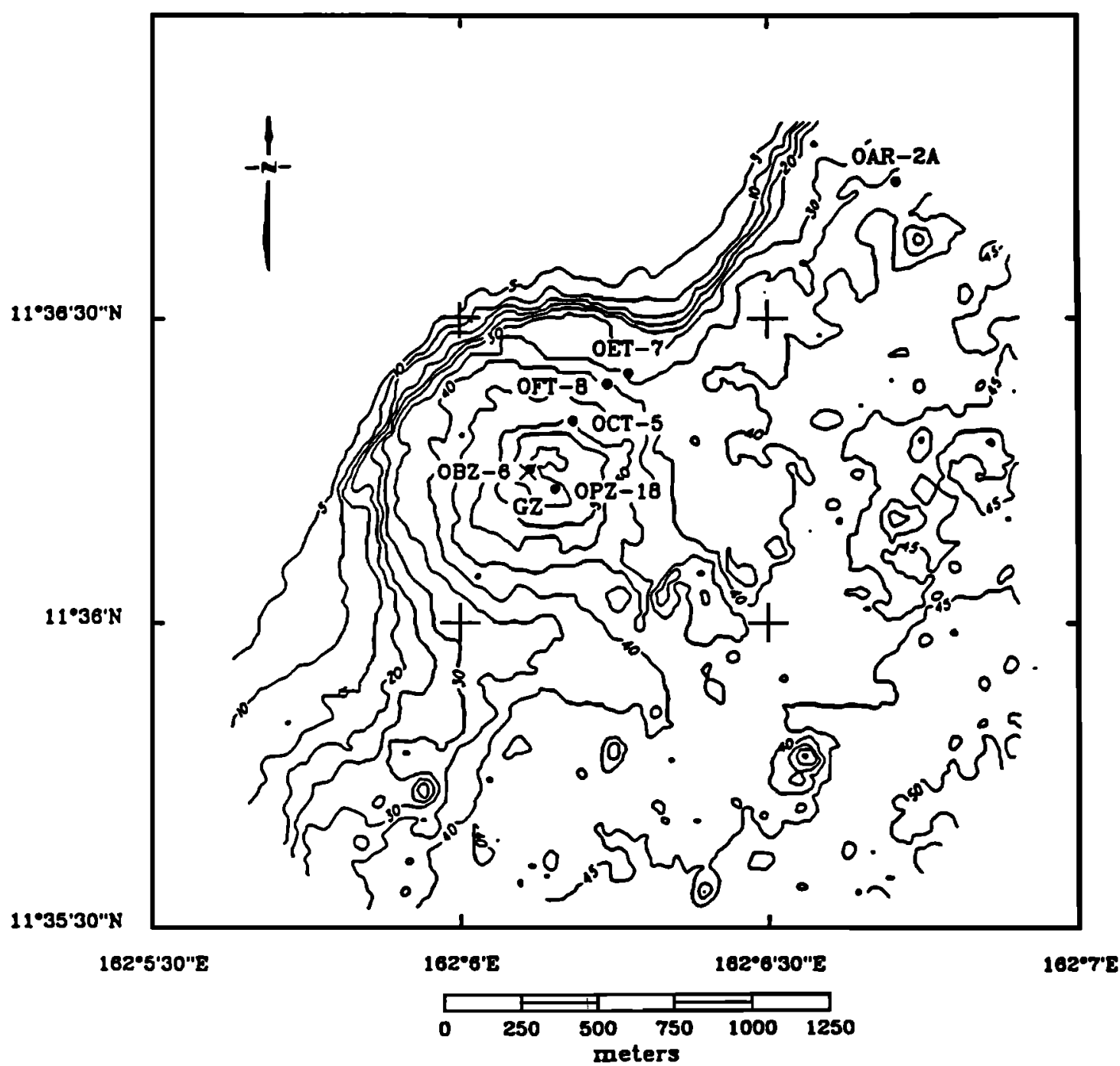

Figure 5. Map of OAK crater [after Folger, 1986] showing the location of the boreholes sampled in this study. Contours are in meters below sea level. OPZ-18 and OPZ-4 are nearly colocated. 
and Gamma zones becomes increasingly less fractured and displaced. This system will be used later when discussing the results of the borehole sample analysis.

\section{Core Sample Selection}

The core samples consisted of sediments from the six boreholes OAR-2A, OBZ-4, OCT-5, OET-7, OFT-8, and OPZ-18. These boreholes are located on a northeast crater radial, which is parallel to the reef structure or the geologic strike of the atoll (Figure 5). Core samples are designated by a borehole name and a depth in meters below sea level ( $\mathrm{m} \mathrm{bsl}$ ).

The carbonate material from Enewetak is extremely inhomogeneous material containing both calcite and aragonite. As mentioned previously, aragonite does not have a detectable EPR spectrum [Low and Zeira, 1972]; therefore, when possible, samples were selected for high calcite content. For example, those samples containing coral replaced by solution-deposited calcite crystals were preferred because they had stronger EPR signals. We believe these calcite crystals formed during a glacial period when the lagoon was a floor above sea level. The choice of good sample material is important to the extent that it provides a consistent base for analysis, and guards against mistaking a sample with an inherently poor EPR spectrum as one being heavily shocked. The difference between the two cases can usually be recognized by visual inspection but is more difficult to assess with numerical techniques. In each core, the majority of samples were taken from depths above the Gamma geologic zone, defined by Wardlaw and Henry, [1986]. A more detailed description of each sample and its spectra can be found in Polanskey and Ahrens [1987]. Complete descriptions of the stratigraphy of each borehole are given by Henry et al. [1986].

\section{Results of Core Sample Analysis}

The two boreholes located directly below the position of the explosive device, ground zero boreholes OBZ-4 and OPZ-18, were the most heavily sampled cores. A very highly shocked layer of uncemented material was found in OPZ-18 between 121.9 and $126.8 \mathrm{~m}$ bsl. This layer was visually distinguishable by the unusual greenish color of the carbonate sand. The shocked zone was broken at $125.7 \mathrm{~m}$ bsl by a thin zone of lighter colored material. The location and nature of this shocked material coincide with a zone of Holocene sediments described by Wardlaw and Henry [1986] as a possible example of material that has been injected. The present results are consistent with such a hypothesis, since this

\section{OAK CRATER BOREHOLE RESULTS}

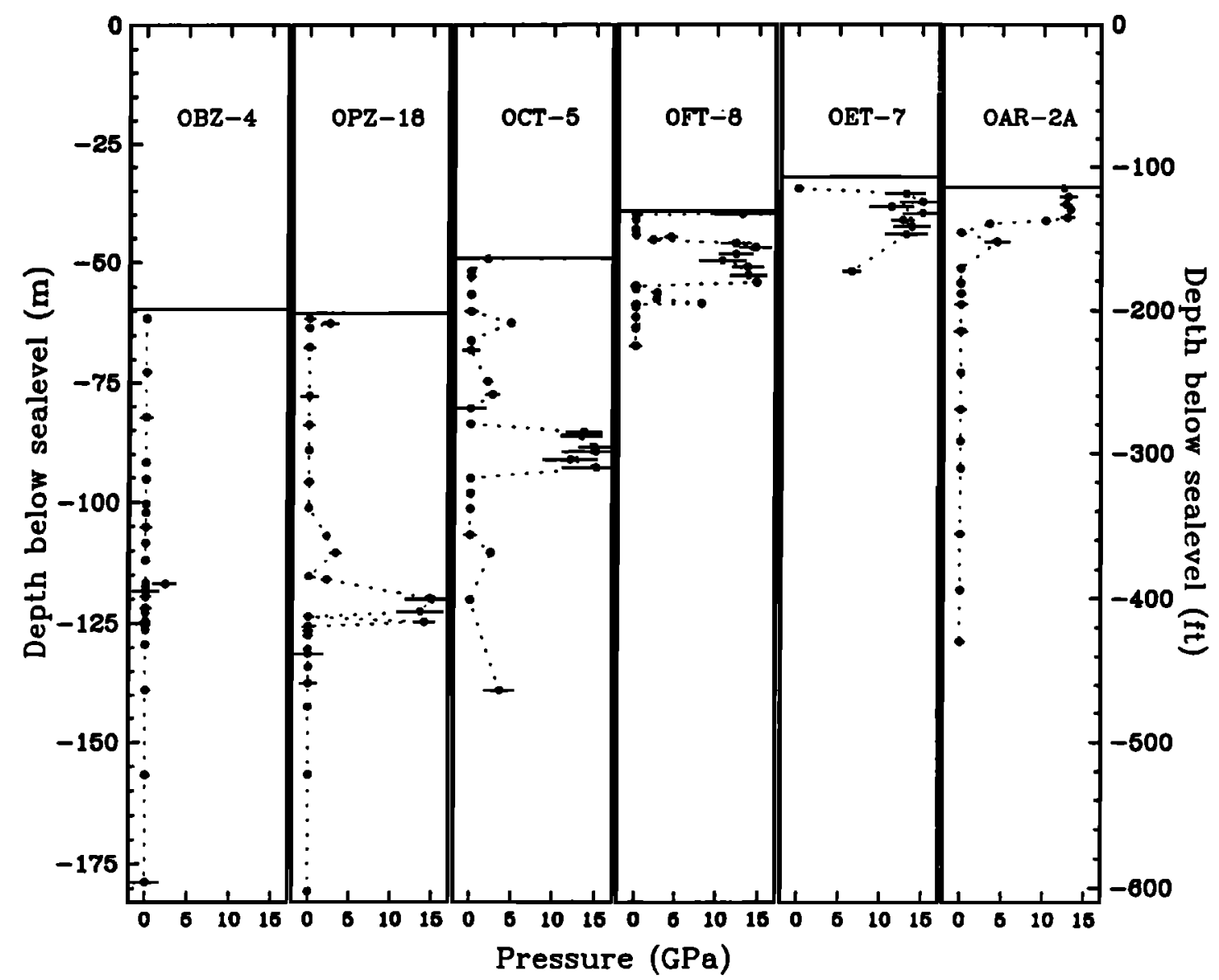

Figure 6a. Results of the borehole sample analysis showing shock pressure versus depth for each borehole. 


\section{HIGHLY SHOCKED MATERIAL IN OAK CRATER}

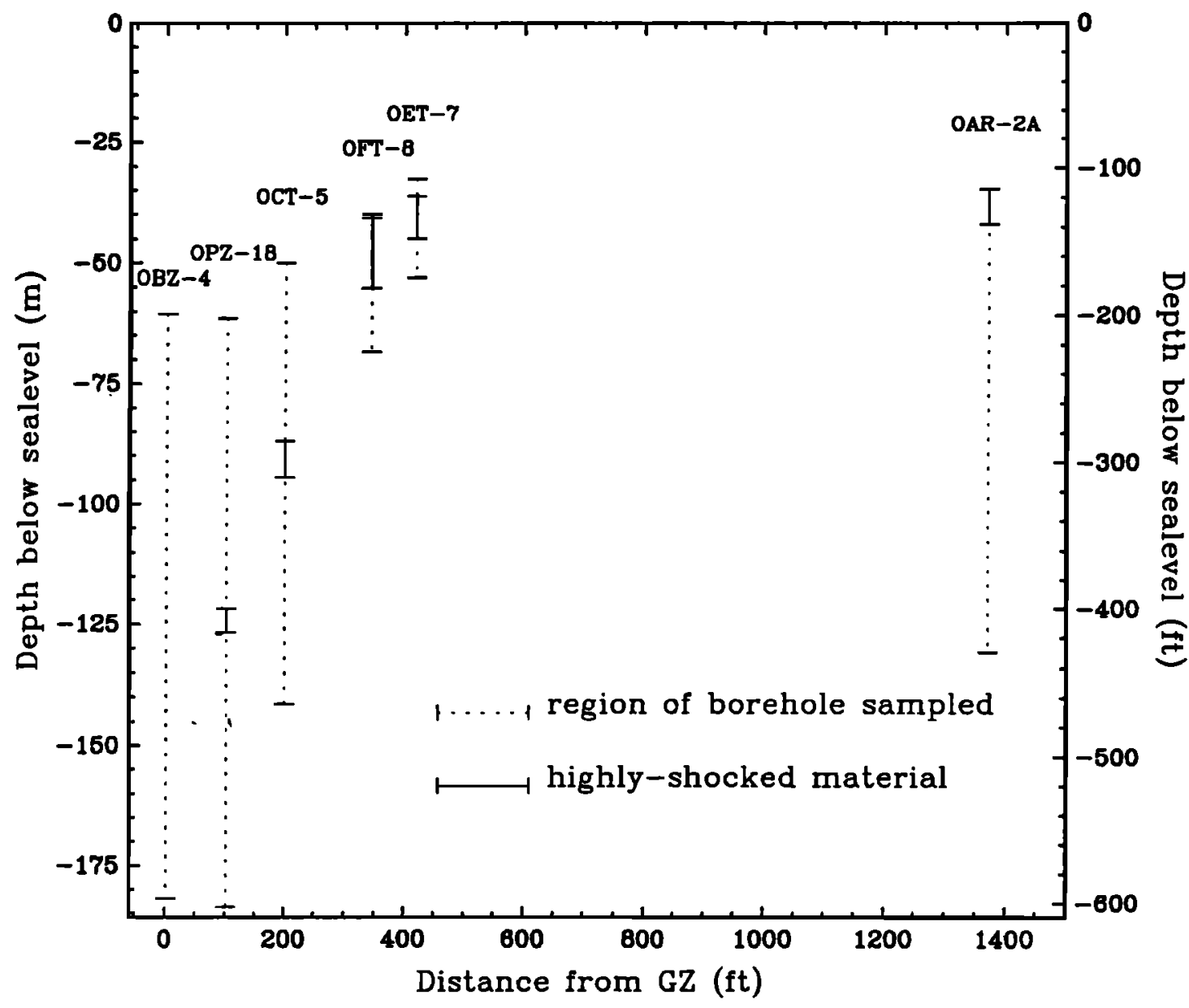

Figure 6b. Results of the core sample analysis showing the depth and thickness of each zone of highly shocked material as a function of distance from ground zero. The dotted line indicates the distance from the current sea floor to the top of the zone, whereas the solid line indicates the region containing highly shocked material.

material most likely originated near the preshot seafloor surface. Three other sand samples above this layer, $117.9,112.3$, and $108.9 \mathrm{~m}$ bsl, were shocked to low levels (Figure 6a). The heavily shocked samples were located primarily in the geologic zone Beta 2, the transition sands, while the lightly shocked material came from the zone Beta 1 [Wardlaw and Henry, 1986]. The remaining 24 of the 31 samples appear to be unshocked. Remarkably, not one of the samples from OBZ-4 showed signs of significant shock damage. There were three samples from the Beta 1 zone that did register marginally detectable degrees of shock damage. Sufficient samples were analyzed from the transition sands and vicinity to characterize the core; therefore, it appears that OBZ-4 did not share the same history as OPZ-18.

Thick zones of highly shocked material were found in each of the three northeastern radial transition boreholes OCT-5, OET-7, and OFT-8. The transition sands have not been identified in any of these boreholes; however, the spectra of the shocked material are similar to those from the shocked material in OPZ-18.
Spectra were taken of 25 samples from borehole OCT5. The results of six samples define a heavily shocked zone at least $7.5 \mathrm{~m}$ thick, extending from 87.0 to $94.4 \mathrm{~m}$ bsl. This region occurs within the Beta $1 \mathrm{~b}$ (early-stage, collapse rubble) zone, and these samples are also primarily uncemented sands. Aside from the highly shocked material in this zone, there are four widely dispersed samples that appear to be moderately shocked. However, one sample in particular, taken at $141.4 \mathrm{~m}$ bsl, is an example of the aforementioned situation, where poor signal quality biases a pressure determination. Simple visual analysis of its spectra suggests that it is actually unshocked. The elevated pressure calculated for this depth is an artifact of the noisiness of the ESR spectra of the sample.

Borehole OFT-8 is located just within the transient crater [Henry et al., 1986]. In this case, the region of heavily shocked material begins near the top of the Beta $1 \mathrm{~b}$ zone and extends downward for approximately $8 \mathrm{~m}$. Included within this zone were seven heavily shocked samples located between 46.8 and $55.1 \mathrm{~m}$ bsl. 
Table 3. Results for OAK Ejecta Samples

\begin{tabular}{cccc}
\hline Sample & Range, $\mathrm{m}$ & $\mathrm{P}, \mathrm{GPa}$ & Source Depth, m bsl \\
\hline 78 & $321 \pm 4$ & $0.0 \pm 0.9$ & - \\
$125 \mathrm{a}$ & $388 \pm 4$ & $0.0 \pm 1.8$ & $61-150$ \\
126 & $369 \pm 4$ & $13.6 \pm 4.0$ & $32-43$ \\
127 & $334 \pm 4$ & $3.0 \pm 2.0$ & - \\
128 & $433 \pm 4$ & $10.5 \pm 8.0$ & $32-43$ \\
144 & $397 \pm 4$ & $12.5 \pm 2.3$ & $32-43$ \\
147 & $357 \pm 9$ & $2.7 \pm 0.9$ & - \\
155 & $396 \pm 4$ & $0.0 \pm 1.4$ & - \\
156 & $338 \pm 4$ & $0.0 \pm 1.1$ & - \\
$156 \mathrm{~b}$ & $338 \pm 4$ & $0.0 \pm 0.9$ & - \\
158 & $276 \pm 4$ & $0.0 \pm 1.0$ & $61-150$ \\
$166 \mathrm{~B}$ & $338 \pm 4$ & $0.0 \pm 1.0$ & $150-210$ \\
$167 \mathrm{~B}$ & $389 \pm 4$ & $0.0 \pm 0.6$ & - \\
$168 \mathrm{~A}$ & $352 \pm 4$ & $0.0 \pm 0.8$ & - \\
$168 \mathrm{C}$ & $342 \pm 4$ & $0.0 \pm 1.4$ & $91-150$ \\
201 & $704 \pm 5$ & $0.0 \pm 1.4$ & 130 \\
$1-1$ & $414 \pm 48$ & $13.1 \pm 1.6$ & $32-43$ \\
$1-2$ & $414 \pm 48$ & $15.0 \pm 3.4$ & $>43$ \\
$1-3$ & $414 \pm 48$ & $14.6 \pm 1.6$ & $32-43$ \\
\hline
\end{tabular}

Source depths are converted to meters below sea level from Ludwig et al. [1986] and B. Ristvet (personal communication, 1981).

Bordering this region above and below are zones containing moderately shocked material. The next farthest borehole from ground zero was OET-7. Based on seismic reflection, paleontology, and lithostratigraphic analysis data, this borehole is thought to be located outside of the transient crater [Henry et al., 1986]. The majority of the samples were from the Gamma zone; however, all but the uppermost sample were heavily to moderately shocked. Of the highly shocked samples, six out of seven were uncemented sediment samples. The highly shocked zone extended from 36.2 to $45.0 \mathrm{~m}$ bsl.

Borehole OAR-2A was initially sampled only as a reference core; however, six surface samples appear to have been heavily shocked. All of the shocked samples were located within the top $12 \mathrm{~m}$ of the core, 33.9 to $45.4 \mathrm{~m}$ bsl, with the most heavily shocked material within the first $7 \mathrm{~m}$. The proximity of this borehole to the reef suggests that highly shocked, fine-grain ejecta may have been deposited from the slope at later times. The combined results from the OAK borehole sample analysis are presented in Figure 6a. The solid horizontal line in each panel indicates the present seafloor depth. The depth and thickness of each zone containing highly shocked material $(P=10 \mathrm{GPa})$ as a function of the distance of the borehole from ground zero are shown in a simplified manner in Figure $6 \mathrm{~b}$.

\section{Results of the Ejecta Sample Analysis}

The OAK ejecta studied consist of 14 samples collected by a submersible from various sites throughout the crater and three samples collected by scuba divers from roughly a single site (Table 3 ). The former samples are a subset of a series of ejecta samples analyzed by Halley et al. [1986]. Figure 7 shows the locations from where each ejecta sample was recovered. The range values were measured from the Figure 7 map. Unfortunately, the ejecta samples in this study were all taken from roughly the same distance from ground zero. There was only one sample, OAK 201, which was recovered at a significantly different range. The results of the ejecta analysis are plotted in Figure 8a. The majority of the ejecta samples were relatively unshocked; however, all of the highly shocked ejecta were found at the base of the reef slope. It is highly unlikely that the reef structure would have blocked the ejection of the highly shocked material during the formation of the transient crater, as the initial ejection angles near surface ground zero are calculationally and experimentally verified to be high angle $\left(>40^{\circ}\right)$. Underwater photos reported by Tremba et al. [1982] and Shinn et al. [1986] strongly support the hypothesis that much of the ejecta was transported down the reef slope during transient crater wall collapse, or later, during the formation of the present crater.

In addition to the range measurements, the estimated preexplosion initial depth of a limited number of the ejecta samples was available from strontium isotopic analyses [Halley et al., 1986] and paleontology (B. Ristvet, personal communication, 1981). The preexplosion depth below seafloor is plotted against shock pressure for these samples in Figure 8b. Although the preexplosion depth estimates are crude, there is a strong correlation between shock pressure and depth for this limited data set. This is consistent, however, with the previous assertion that the surface material was the most severely shocked. 


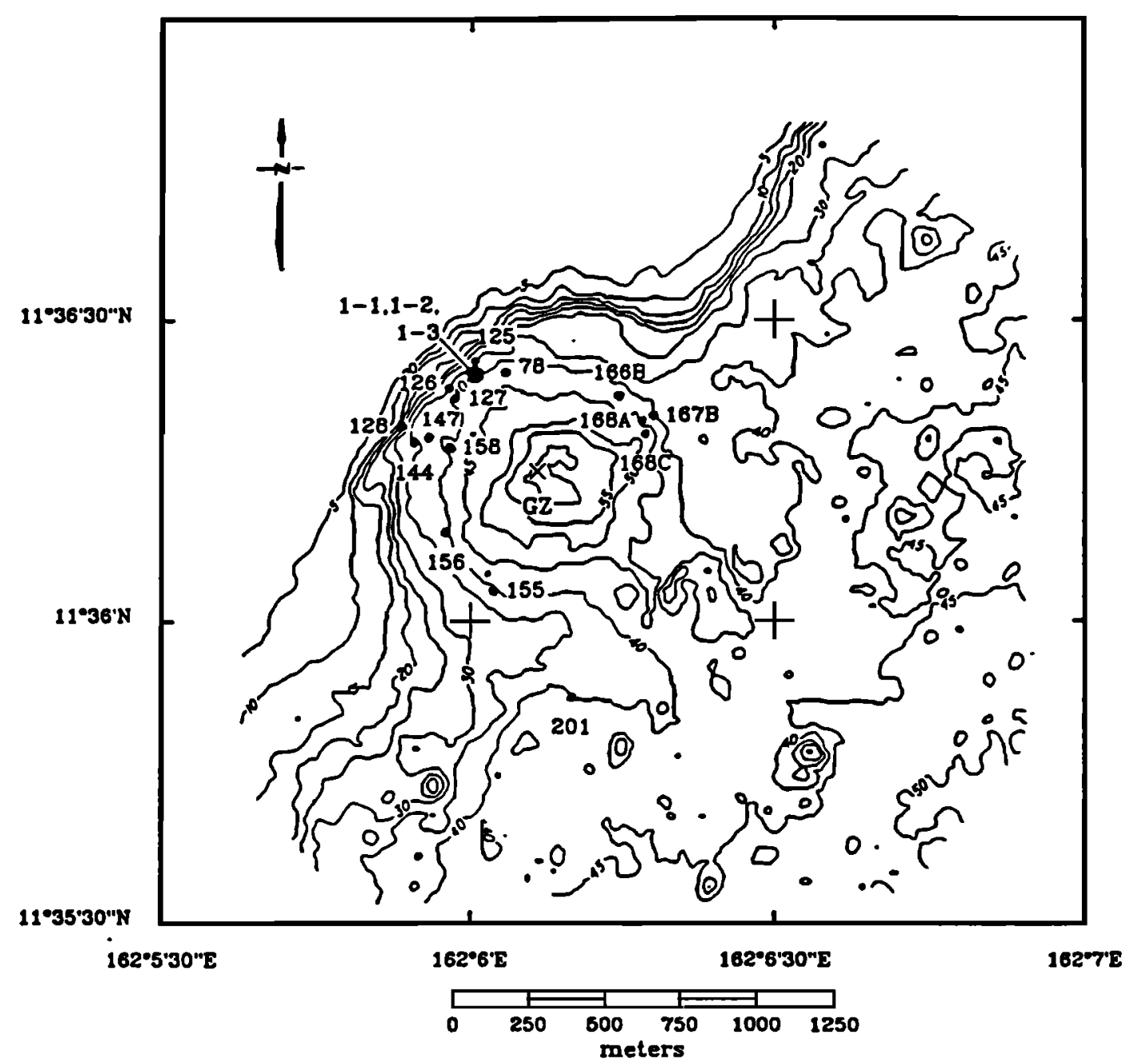

Figure 7. Map of OAK crater showing ejecta recovery sites. Origin of map same as Figure 5.

\section{Interpretation of OAK Crater}

With a few exceptions, the bulk of the samples analyzed can be split into two categories, unshocked and very heavily shocked. There were relatively few samples that are assigned to intermediate pressures. The lack of samples at intermediate shock pressures suggests that the majority of the shocked material shares a common origin, which appears to be initially near-surface material which outlines the original transient crater. Below this heavily shocked material, the rock core samples, although deformed, are in proper stratigraphic sequence. Above the heavily shocked zone the sediment and rock in the crater appear to be fallout ejecta material introduced into the crater after the explosion via shockinduced liquefaction [Tremba et al. , 1990], and subsequent wave and storm sediment transport.

Assuming the highly shocked material shown in Figure 6 represents the outline of the present shape of the transient cavity and this cavity is circularly symmetric, a volume of $3.6 \pm 0.2 \times 10^{6} \mathrm{~m}^{3}$ is calculated from the data of Figure 6 . Because of postexplosion upward deformation, this volume should be considered a lower bound. Notably, Tremba et al. [1990] on the basis of this and other geologic data, inferred a transient crater with nearly twice this volume of $6.8 \times 10^{6} \mathrm{~m}^{3}$. Schmidt et al. [1986] have developed a scaling relation for both the volume of the final crater and transient cavity versus energy for surface explosions in water-saturated rock. Here, in cgs units,

$$
(V / E)=5.2 \times 10^{-7} E^{-0.2}
$$

Equation (4) indicates that the volume excavated $(V)$ divided by explosive energy, $E$, decreases with increasing energy. Small-scale model explosive experiments conducted under high gravities generated in the Boeing centrifuge facility indicate that the volume of the transient cavity is 1.4 times that of the final crater. Equation (4) yields a final crater volume of $3.7 \times 10^{6}$ $\mathrm{m}^{3}$ and hence, a transient crater volume (a factor of 1.4 greater) of $5.2 \times 10^{6} \mathrm{~m}^{3}$, in good agreement with the Tremba et al. [1990] value.

\section{Meteor Crater}

Meteor Crater is $180 \mathrm{~m}$ deep and $1.2 \mathrm{~km}$ in diameter. It is located in north-central Arizona on the Colorado 
a)

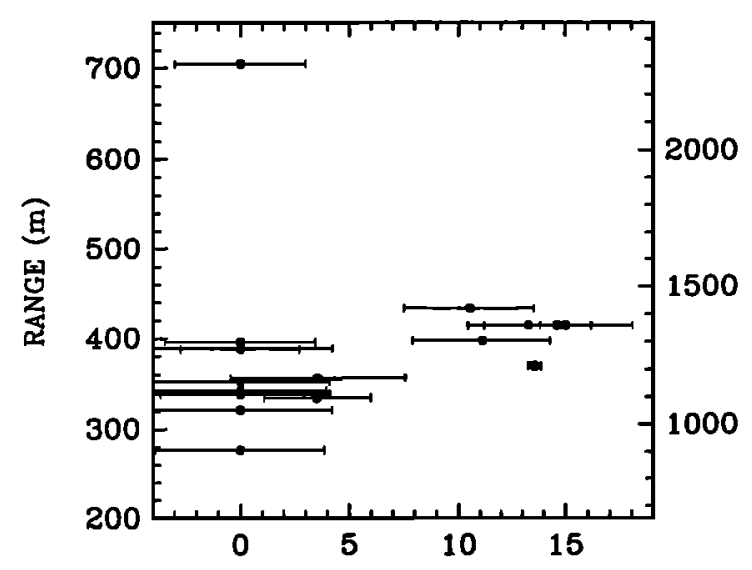

b)

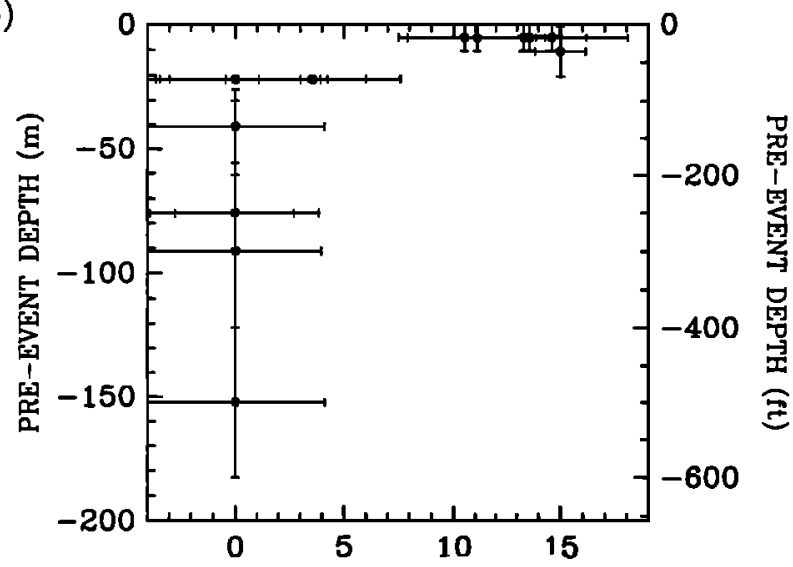

Figure 8. Results of the OAK Crater ejecta sample analysis showing (a) shock pressure as a function of range from ground zero, and (b) estimated preexplosion depth below seafloor versus shock pressure for a subset of the ejecta samples.

Plateau. The crater was formed in flat-lying bedrock consisting of the Moenkopi, Kaibab, Coconino, and Toroweap formations [Shoemaker and Kieffer, 1974]. Thermoluminescence studies of the Coconino sandstone and the Kaibab dolomite give an age of 49,000 years for the crater [Sutton, 1985].

Unlike the previous discussion of OAK Crater, the analysis of the Meteor Crater samples is less complete. The Kaibab Formation data set is divided into five sections: pressure calibration experiments (discussed above), Diablo Canyon unshocked Kaibab standards, samples from the walls of Meteor Crater, Meteor Crater ejecta samples, and a miscellaneous category including breccia samples and highly shocked Kaibab Formation ejecta subsequently redeposited inside the crater. A complete catalog of these spectra is given by Polanskey [1989].

Although the effects of shock pressure on Kaibab Formation samples have been demonstrated in Figure $2 b$, shock pressure may not be the only variable. As mentioned previously, the $\mathrm{Mn}^{2+}$ may substitute in both the $\mathrm{Mg}$ and Ca sites of the dolomite structure. The distribution of $\mathrm{Mn}^{2+}$ between these sites will affect the shape of the resulting spectrum. Therefore, differences in the $\mathrm{Mn}^{2+}$ distribution between the various members of the Kaibab Formation could confuse the effects of shock pressure. The spectra from a series of Kaibab samples taken from Diablo Canyon (16 km east of Meteor Crater) are presented by Polanskey [1989]. Although the calibration equations (3a) and (3b) were defined using the high-resolution spectra constructed from an average of the Diablo Canyon samples, the calibration was still applied to aliquots of the unshocked samples as a self-consistency test. The results are listed in Table 4 and show that in most cases the expected zero pressure was obtained. The pressure of $0.1 \mathrm{GPa}$ calculated for sample 2 illustrates the limitations in accuracy of this analysis. A sample of caliche was also processed in order to determine whether or not weathering products would influence the analysis. The caliche spectrum was clearly distinguishable from the Kaibab spectra.

\section{Results of the Meteor Crater Sample Analysis}

The results for the crater wall analysis are listed in Table 5. There is a slight indication of shock damage in the 0.3 to $0.6 \mathrm{GPa}$ range in the samples from the $\beta$ member of the Kaibab formation.

The peak pressure range experienced by some Kaibab limestone samples from the crater wall may be used to place constraints on the energy of the impactor using the relations derived by Moss [1988] and Lamb et al. [1991] for free-field shock pressure versus radius. Since we have in situ sampled rocks which lie not beneath the crater, which is less affected by the free surface, but a zone close to the free surface which may have experienced less than the free field shock pressure on account of stress wave reflections at the free surface [Melosh, 1984], lower bounds on the impactor energy can only be obtained.

The Moss-Lamb model assumes that for an explosion in the free field the total energy, $W$, is uniformly de-

Table 4. Results for Diablo Canyon Samples

\begin{tabular}{ccl}
\hline Sample Number & Pressure, GPa & \multicolumn{1}{c}{ Description } \\
\hline 1 & $0.0 \pm 0.03$ & mid- $\alpha$ member, near surface \\
2 & $0.1 \pm 0.01$ & lower- $\alpha$ member \\
3 & $0.0 \pm 0.05$ & upper $-\beta$ member, near contact to $\alpha$ member \\
4 & $0.0 \pm 0.01$ & mid- $\beta$ member, $30 \mathrm{ft}(10 \mathrm{~m})$ into member \\
5 & $0.0 \pm 0.03$ & $60-70 \mathrm{ft}(18-21 \mathrm{~m})$ into $\beta$ member \\
\hline
\end{tabular}


Table 5. Results for Meteor Crater Wall Samples

\begin{tabular}{ccl}
\hline Sample Number, & Pressure, GPA & \multicolumn{1}{c}{ Description } \\
\hline 1 & $0.0 \pm 0.02$ & uppermost $\alpha$ member, contact Kaibab/Moenkopi \\
2 & $0.0 \pm 0.02$ & upper $\alpha$ member, below yellow vuggy dolomite \\
3 & $0.1 \pm 0.02$ & lower $\alpha$ member, below breccia \\
4 & $0.3 \pm 0.04$ & uppermost $\beta$ member, above promontory \\
5 & $0.5 \pm 0.06$ & upper $\beta$ member, above promontory \\
6 & $0.6 \pm 0.08$ & lower $\beta$ member, near promontory \\
7 & $0.4 \pm 0.05$ & lower $\beta$ member, near Astronaut trail \\
8 & $0.1 \pm 0.02$ & $\gamma$ member, base of promontory \\
\hline
\end{tabular}

posited within a spherical shock of radius, $R$, and the internal energy and kinetic energy per unit mass are equal; then

$$
f W=u^{2}\left(\rho_{\circ} \frac{4}{3} \pi R^{3}\right)
$$

Here $f$ is an efficiency factor which takes into account that because of irreversible energy deposition only a fraction of the energy is available to drive a shock. Also, $u$ is the outward particle velocity of the shock wave, and $\rho_{o}$ is the initial medium density. The term within the parentheses is the mass encompassed by the shock and $f$ would be unity if the work done on the rock within the sphere was all reversible. By fitting the observed decays of the stress waves from a large number of nuclear explosions, both in wet and dry rocks, Moss found that $f \approx 0.53$. For many dry and wet media the shock velocity versus particle velocity is given as

$$
U_{s}=C_{o}+s u
$$

Here $\mathrm{C}_{o}$ and $s$ are the parameters for Kaibab limestone of Table 1. The shock pressure is given by the Rankine Hugoniot equation

$$
P=\rho_{o} U_{s} u
$$

Upon substituting $\mathrm{U}_{s}$ from (6) in (7) and then eliminating $u$, between (5) and (7), we solve the resulting expression for $W$ using the 0.53 value for $f$. Assuming a peak value of pressure (Table 4) from samples taken at a $0.533-\mathrm{km}$ radius from the crater center of $0.6 \pm$ $0.08 \mathrm{GPa}$ yields an impactor energy, $W$, of $8.9 \pm 2.3$ $\mathrm{Mt}$, whereas a lower value of $0.3 \pm 0.04 \mathrm{GPa}$ yields an impact energy of $2.41 \pm 0.65 \mathrm{Mt}$. We use the greater of these bounds to test the Schmidt and Housen [1987] gravity cratering scaling law for wet granular media. This is given by

$$
\Pi_{r}=0.8 \Pi_{2}^{-0.22}
$$

where

$$
\Pi_{r}=R\left(\rho_{o} / m\right)^{1 / 3}
$$

where $m$ is the mass of the impactor, $\rho_{o}$ is the initial density of the medium, and $R$ is the crater radius. Also

$$
\Pi_{r}=3.22 \mathrm{ga} / U^{2}
$$

where $g$ is gravity, $a$ and $U$ are the projectile radius and impact velocity. Numerical calculational fits of the theoretical crater to the observed crater have assumed values of $51 \times 10^{9}$ to $167 \times 10^{9} \mathrm{~g}$ [e.g., Roddy et al., 1980; Bryan et al., 1978] for an assumed iron-nickel, density $7.86 \mathrm{~g} / \mathrm{cm}^{3}$ bolide. Using a crater radius of $0.533 \mathrm{~km}$, and an average water-saturated target density of $2.35 \mathrm{~g} / \mathrm{cm}^{3}$ in (8)-(10) yields an impactor energy of 4.06 and $3.30 \mathrm{Mt}$, over the range of bolide masses assumed. These energy estimates are in good agreement but somewhat lower than our maximum energy of 8.9 $\pm 2.3 \mathrm{Mt}$ inferred from the peak shock pressure seen by rock in the crater wall.

Another approach to using the present available theory of Schmidt and Housen is to employ the calculation of crater volume from Roddy [1978].

Analogous to (9) is:

$$
\Pi_{2}=\rho V / m
$$

where $\rho$ is the density of the target $\left(2.35 \mathrm{~g} / \mathrm{cm}^{3}\right), V$ is Roddy's [1978] value of $75 \times 10^{12} \mathrm{~cm}^{3}$ for the "apparent crater volume," and $m$ is the assumed bolide mass, here again taken to range from 51 to $167 \times 10^{9} \mathrm{gm}$. Using the definition of $\Pi_{v}$ as

$$
\Pi_{v}=3.22 g a / U^{2}
$$

and the Schmidt and Housen [1987] equation

$$
\Pi_{v}=0.2 \Pi_{2}^{-0.65}
$$

we solve (11), (12), and (13) for $U$ (impact velocity) for the smaller and larger assumed iron-nickel bolide mass to obtain 34.8 and $17.0 \mathrm{~km} / \mathrm{s}$. These impact velocities then yield impact energies of 7.4 and $5.8 \mathrm{Mt}$, respectively. These are somewhat larger energies than originally estimated by Shoemaker [1963] (of 1.2 to 1.8 $\mathrm{Mt}$ ) on the basis of cube-root scaling from the nuclear craters.

Finally, we note there was also some evidence of light shock damage in the ejecta samples (Table 6). Figure 9 shows a plot of shock pressure versus distance from the crater rim for the Meteor Crater ejecta. As in the case of OAK Crater ejecta, the majority of the samples appear to be unshocked. However, there was some bias in the ejecta sampling technique. All the ejecta samples 
Table 6. Results for Meteor Crater Ejecta Samples

\begin{tabular}{ccc}
\hline Sample & Pressure, GPa & Range, m \\
\hline 1 & $0.0 \pm 0.04$ & 1414 \\
2 & $0.3 \pm 0.04$ & 1240 \\
3 & $0.0 \pm 0.07$ & 1240 \\
4 & $0.5 \pm 0.08$ & 1212 \\
5 & $0.1 \pm 0.02$ & 1183 \\
6 & $0.0 \pm 0.07$ & 1178 \\
7 & $0.0 \pm 0.06$ & 1082 \\
$8 \mathrm{~A}$ & $0.0 \pm 0.06$ & 928 \\
$8 \mathrm{~B}$ & $0.1 \pm 0.04$ & 928 \\
9 & $0.0 \pm 0.01$ & 350 \\
10 & $0.4 \pm 0.08$ & 284 \\
11 & $0.6 \pm 0.05$ & 140 \\
\hline
\end{tabular}

were taken from large boulders within the ejecta field. The results could change if more samples were taken over a complete distribution in ejecta size. No sign of the $\mathrm{Mn}^{2+}$ spectrum was found for ejecta samples which had been partially melted as a result of the impact. In this material the carbonate phases were probably not present.

\section{Summary}

The comparison of EPR spectra from samples shocked in the laboratory with those subjected to impact and explosion-induced shocks has been shown to be a useful technique in the analysis of craters in carbonate rocks. In OAK Crater we were able to detect for the first time, the highly shocked (10-13 GPa) lining

\section{METEOR CRATER EJECTA}

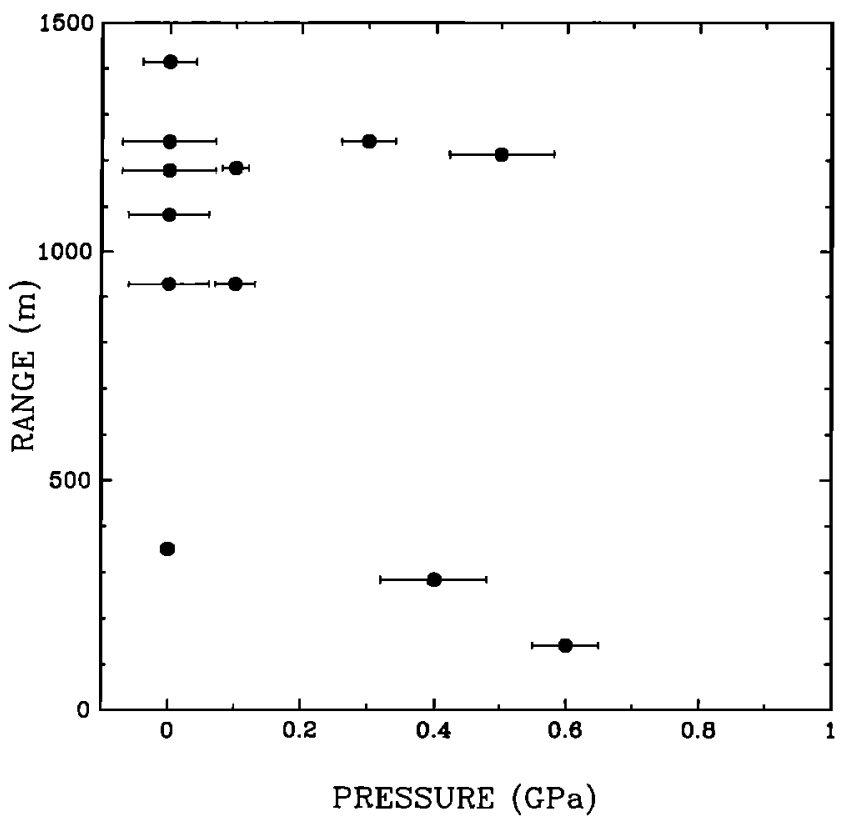

Figure 9. Results of the Meteor Crater ejecta sample analysis showing shock pressure as a function of range from the crater rim. of the transient crater beneath the apparent crater. It should be emphasized that this material has undergone substantial uplift and other motion since it lined the transient crater.

The volume of this lining, $3.2 \pm 0.2 \times 10^{6} \mathrm{~m}^{3}$ at a depth of $125 \mathrm{~m}$ below sea level beneath a $60 \mathrm{~m}$ cover of fallback ejecta and other material at the center of the crater provides a test of the scaling for transient craters proposed by Schmidt et al. [1986]. They propose on the basis of small-scale laboratory experimentation, a relation for the transient cavity produced by a surface explosion of

$$
V=7.3 \times 10^{-7} E^{0.8} \quad \text { (cgs units) }
$$

For a known yield, $\left(4^{\prime}\right)$ predicts a volume of $5.3 \times 10^{6}$ $\mathrm{m}^{3}$. Since our experimental estimate of transient crater volume, $3.2 \pm 0.2 \times 10^{6} \mathrm{~m}^{3}$ is a lower bound, we consider the agreement good. The occurrence of heavily shocked (10-15 GPa) ejecta, which had an initial shallow depth in the carbonate reef material of only 32 to $43 \mathrm{~m}$, is in general accord with crater models which predict that initial surface materials should be more heavily shocked.

The demonstration that the carbonate rocks of the 49,000-year-old Barringer, Arizona (Meteor), Crater retain the shock-induced internal deformation signature suggests that ESR methods can be utilized in the study of geologically young craters in carbonate terranes.

Kaibab limestone ejecta cobbles and carbonate in situ in the walls of the crater demonstrate the effects of shock deformation to stress levels of 0.3 to $0.6 \mathrm{GPa}$. Using this peak shock pressure and the Moss [1988] and Lamb et al. [1991] relations for shock pressure versus radius for explosion-induced shock wave decay in the free field of $2.41 \pm 0.65$ and $8.9 \pm 2.3 \mathrm{Mt}$ is inferred for the bolide energy required to produce Meteor Crater. This value is comparable to those obtained from the Schmidt and Housen [1987] scaling law which, depending on assumptions regarding the bolide mass, yield impact energies of 3.3 to $4.1 \mathrm{Mt}$ for crater radius scaling. If instead we use the inferred apparent true crater volume of Roddy [1978], their scaling relations imply an energy of 5.8 to $7.4 \mathrm{Mt}$.

Thus, we conclude that in the case of Meteor Crater, the peak shock pressure seen by in situ carbonate rocks on the rim (0.3 to $0.6 \mathrm{GPa}$ ) give impact energies (2.4-8.9 $\mathrm{Mt}$ ), which are in good agreement derived from modern theories (3.3. to $7.4 \mathrm{Mt}$ ) of the energetics of impact cratering.

Acknowledgments. Research supported by NASA and DNA. We thank Robert Couch, Jr., for technical advice and support of the Enewetak project and Thomas W. Henry, Robert Halley, and Byron Ristvet for assistance in sample acquisition. Eugene Shoemaker, David Roddy, and Ralph Hopkins helped us collect samples from Meteor Crater and Diablo Canyon. Papo Gelle, Mike Long, and Leon Young assisted with the shock wave experiments. The use of the Caltech EPR facilities under the direction of Sunney Chan is appreciated. Comments on the manuscript from Joana Viz- 
girda, Byron Ristvet, David Live, and Fun-dow Tsai were most helpful. Division of Geological and Planetary Sciences, California Institute of Technology, Pasadena, contribution 4704.

\section{References}

Ahrens, T. J., and V. G. Gregson, Shock compression of crustal rocks: Data for quartz, calcite, and plagioclase rocks, J. Geophys. Res., 69, 4839-4874, 1964.

Blanchard, S. C., and N. D. Chasteen, Electron paramagnetic resonance spectrum of a sea shell: Mytilus edulis. $J$. Phys. Chem., 80, 1362-1367, 1976.

Bryan, J. B., D. E. Burton, M. E. Cunningham, and L. A. Lettis, Jr., A two-dimensional computer simulation of hypervelocity impact cratering: Some preliminary results for Meteor Crater, Arizona. Proc. Lunar Planet. Sci. Conf., 9th, Geochim. Cosmochim. Acta, 3, 3931-3964, 1978.

Dunham, R. J., Classification of carbonate rocks according to depositional texture, in Classification of Carbonate Rocks, A Symposium, Mem. 1, edited by W. E. Ham,pp. 18-121, American Association of Petroleum Geologists, Tulsa, Okla., 1962.

Folger, D. W., Sea-floor observations and subbottom seismic characteristics of OAK and KOA Craters, Enewetak Atoll, Marshall Islands, U.S. Geol. Surv. Bull., 1678, 301 pp., 1986.

Grieve, R.A.F., The record of impact on Earth: Implications for a major Cretaceous/Tertiary impact event, in Geological Implications of Impacts of Large Asteroids and Comets on the Earth, Spec. Pap. 190, edited by L.T. Silver and P.H. Schultz, pp. 25-68, Geological Society of America, Boulder, Colo., 1982.

Grolier, Bibliography of terrestrial impact structures, NASA Tech. Memor. TM-87567, 548 pp., 1985.

Halley, R. B., R. P. Major, K. R. Ludwig, Z. L. Peterman, and R. K. Matthews, Preliminary analyses of OAK debris samples, Sea-floor observations and subbottom seismic characteristics of $O A K$ and KOA craters, Enewetak Atoll, Marshall Islands, U.S. Geol. Surv. Bull., 1678, G1-G11, 1986.

Henry, T. W., and B. R. Wardlaw, Pacific Enewetak Atoll Crater Exploration (PEACE) Program Enewetak Atoll, Republic of the Marshall Islands, Part 4: Analysis of borehole gravity surveys and other geologic and bathymetric studies in vicinity of OAK and KOA crater, U.S. Geol. Surv. Open File Rep. 87-665, 1987.

Henry, T. W., B. R. Wardlaw, B. Skipp, R. P. Major, and J. I. Tracey, Jr., Pacific Enewetak Atoll Crater Exploration (PEACE) Program Enewetak Atoll, Republic of the Marshall Islands, Part 1: Drilling operations and descriptions of boreholes in vicinity of KOA and OAK craters, U.S. Geol. Surv. Open File Rep. 86-419, 1986.

Hurd, F. K., M. Sachs, and W.D. Hershberger, Paramagnetic resonance absorption of $\mathrm{Mn}^{++}$in single crystals of $\mathrm{CaCO}_{3}$, Phys. Rev., 93, 373-380, 1954.

Isbell, W. M., F. H. Shipman, and A. H. Jones, Hugoniot equation of state measurements for selected geological materials, Q. Prog. Rep. 2, NAS 2-3427, 8 pp., General Motors Res. Lab., Warren, Mich., 1966.

Lamb, F. K., B. W. Callen, and J. D. Sullivan, Yield estimation using shock wave methods, in Explosion Source Phenomenology, Geophys. Monogr. Ser., vol. 65, edited by S. R. Taylor, H. J. Patton, and P. G. Richards, pp. 73-89, AGU, Washington, D.C., 1991.

Lange, M. A., and T. J. Ahrens, Shock-induced $\mathrm{CO}_{2}$ loss from $\mathrm{CaCO}_{3}$ : Implications for early planetary atmospheres, Earth Planet. Sci. Lett., 77, 409-418, 1986.
Low, W., and S. Zeira, ESR spectra of $\mathrm{Mn}^{++}$in heat-treated aragonite, Am. Mineral., 57, 1115-1124, 1972.

Ludwig, K. R., R. B. Halley, K. R. Simmons, and Z. E. Peterman, Sr-isotope stratigraphy of disturbed and undisturbed carbonates, Pacific Enewetak Atoll Crater Exploration (PEACE) Program Enewetak Atoll, Republic of the Marshall Islands, Part 3: Stratigraphic analysis and other geologic and geophysical studies in vicinity of OAK and KOA craters, U.S. Geol. Surv. Open File Rep. 86-555, 1986.

Mankowitz, J., and W. Low, Forbidden transitions $(\Delta \mathrm{m}= \pm 1)$ in the paramagnetic resonance absorption of $\mathrm{Mn}^{2+}$ in calcite, Phys. Rev. B., 2, 28-32, 1970.

Marsh, S. P. (Ed.), LASL Shock Hugoniot Data, 658 pp., University of California Press, Berkeley, 1980.

Melosh, H. J., Impact ejection, spallation, and the origin of meteorites, Icarus, 59, 234-260, 1984.

Moss, W. C., A method to estimate the yield of an underground nuclear explosion, J. Appl. Phys., 63, 4771-4773, 1988.

Polanskey, C. A., Craters in carbonate rocks: An electron paramagnetic resonance analysis of shock damage, Ph.D. Thesis, Part 2, pp. 41-125, Calif. Inst. of Technol., Pasadena, CA, 1989.

Polanskey, C. A., and T. J. Ahrens, Electron paramagnetic resonance studies of selected borehole samples and debris material from OAK crater, Pacific Enewetak Atoll Crater Exploration (PEACE) Program Enewetak Atoll, Republic of the Marshall Islands, Part 4: Analysis of borehole gravity survey and other geologic and bathymetric studies, U.S. Geol. Surv. Open File Rep. 87-665, 1987.

Prissok, F., and G. Lehmann, An EPR study of $\mathrm{Mn}^{2+}$ and $\mathrm{Fe}^{3+}$ in dolomites, Phys. Chem. Miner., 13, 331-336, 1986.

Ristvet, B. L., Geology and geohydrology and Enewetak Atoll, in The Natural History of Enewetak Atoll, Vol. I, The Ecosystem: Environments, Biotas, and Processes, DOE/EV/00703-T1, vol. 1, edited by D. M. Devaney, E. S. Reese, B. L. Burch, and P. Helfrich, pp. 37-56, U.S. Department of Energy, Office of Scientific and Technical Information, Oak Ridge, Tenn., 1987.

Ristvet, B. L., E. L. Tremba, R. F. Couch, Jr., J. A. Fetzer, E. R Goter, D. R. Walter, and V. P. Wendland, Geologic and geophysical investigations of the Enewetak nuclear craters, AFWL-TR-77-242, 300 pp., Air Force Weapons Lab., Kirtland Air Force Base, N. Mex., 1977.

Roddy, D. J., Pre-impact geologic conditions, physical properties, energy calculations, meteorite, and initial crater dimensions, and orientations of joints, faults, and wall at Meteor Crater, Arizona, Proc. Lunar Planet. Sci. Conf., 9th, Geochim. Cosmochim. Acta, 3, 3890-3930, 1978.

Roddy, D. R., S. H. Schuster, K. N. Kreyenhagen, and D. L. Orphal, Computer code simulations of the formation of Meteor Crater, Arizona: Calculations MC-1 and MC-2., Lunar Planet. Sci. Conf., 11th, 2275-2308, 1980.

Schmidt, R. M., and K. R. Housen, Some recent advances in the scaling of impact and explosion cratering, Int. $J$. Impact Eng., 5, 543-560, 1987.

Schmidt, R. M., K. A. Holsapple, and K. R. Housen, Gravity effects in cratering, Pacific Enewetak Atoll Crater Exploration (PEACE) Program Enewetak Atoll, Republic of the Marshall Islands, Rep. DNA-TR-86-182, Defense Nucl. Agency, Washington, D.C., 1986.

Shinn, E. A., J. L. Kidinger, R. B. Halley, and J. H. Hudson, Scuba observations of OAK and KOA craters, $\mathrm{Pa}$ cific Enewetak Atoll Crater Exploration (PEACE) Program Enewetak Atoll, Republic of the Marshall Islands, Seaflooor observations and subbottom seismic characteristics of OAK and KOA craters, Enewetak Atoll, Marshall Islands, U.S. Geol. Surv. Bull., 1678, 1986. 
Shoemaker, E. M., and S. Kieffer, Synopsis of the geology of Meteor Crater, in Guidebook to the Geology of Meteor Crater, paper presented at the annual meeting of the Meteoritical Society, Aug. 1974.

Shoemaker, E. M., Impact mechanics at Meteor Crater, Arizona, in Moon, Meteorites, and Comets, edited by B. M. Middlehurst and G. P. Kuiper, pp. 301-336, University of Chicago Press, Chicago, Ill., 1963.

Short, N.M., and T. E. Bunch, A worldwide inventory of features characteristic of rocks associated with presumed meteorite impact structures, in Shock Metamorphism of Natural Materials, edited by B.M. French and N.M. Short, pp. 255-266, Mono Book Corp., Baltimore, Md., 1968.

Stöffler, D., Deformation and transformation of rock- forming minerals by natural and experimental shock processes, Fortschr. Mineral., 49, 50-113, 1972.

Sutton, S. R., Thermoluminescence measurements on shockmetamorphosed sandstone and dolomite from Meteor Crater, Arizona, 2, Thermoluminescence age of Meteor Crater, J. Geophys. Res., 90, 3690-3700, 1985.

Tremba, E. L., R. F. Couch, Jr., and B. L. Ristvet, in Enewetak Atoll Seismic Investigation (EASI), Phases I and II, AFWL-TR-82-20, Air Force Weapons Lab, Kirtland Air Force Base, N. Mex., NM, 1982.

Tremba, E. L., B. L. Ristvet, B. R. Wardlaw, T. W. Henry, J. F. Schatz, and R. F. Couch, A summary of the interim findings, Pacific Enewetak Atoll Crater Exploration (PEACE) Program, Enewetak Atoll, Republic of the Marshall Islands, Rep. DNA-TR-88-289, Defense Nucl. Agency, Washington, D.C., 1990.
Tyburczy, J. A., and T. J. Ahrens, Dynamic compression and volatile release of carbonates, J. Geophys. Res., 91, 4730-4744, 1986.

Vinokurov, V. M., M. M. Zaripov, and V. G. Stepanov, A study of some Mn-containing carbonates by the method of electron paramagnetic resonance, Sov. Phys. Crystal$\log r ., 6,83-86,1961$.

Vizgirda, J., T. J. Ahrens, and F. Tsay, Shock-induced effects in calcite from Cactus Crater, Geochim. Cosmochim. Acta., 44, 1059-1069, 1980.

Wardlaw, B. R., and T. W. Henry, Geologic interpretation of OAK and KOA craters, Pacific Enewetak Atoll Crater Exploration (PEACE) Program Enewetak Atol, Republic of the Marshall Islands, Part 3: Stratigraphic analysis and other geologic and geophysical studies in vicinity of OAK and KOA craters, U.S. Geol. Surv. Open File Rep. 86-555, 1986.

Wildeman, T. R., The distribution of $\mathrm{Mn}^{2+}$ in some carbonates by electron paramagnetic resonance, Chem. Geol., 5, 167-177, 1970.

T. J. Ahrens, Seismological Laboratory, MS 252-21, California Institute of Technology, Pasadena, CA 91125.

C. A. Polanskey, Jet Propulsion Laboratory, 4800 Oak Grove Drive, Pasadena, CA 91109.

(Received November 2, 1992; revised November 3, 1993; accepted December 17, 1993.) 